07

\title{
Оконные стекла - состояние и перспективы
}

\author{
(C) В.А. Майоров \\ Новгородский государственный университет имени Ярослава Мудрого, \\ 173003 Великий Новгород, Россия \\ e-mail: Vitaly.Mayorov@novsu.ru
}

Поступила в редакцию 22.10.2017 г.

Выполнены анализ и обобщение результатов исследований по совершенствованию оптических свойств и приведены описания структуры и механизма взаимодействия с солнечным излучением существующих и перспективных оконных стекол. Все устройства разделены на группы со статическими неизменными и динамическими регулируемыми спектральными характеристиками. Группу статических стекол составляют теплозащитные и спектрально-селективные стекла с низкоэмиссионными покрытиями, а также инфракрасные фильтры с диспергированными плазмонными наночастицами. К динамическим устройствам относятся электрохромные стекла, а также наноструктурные динамические инфракрасные фильтры и стекла с раздельным регулированием пропускания видимого света и ближнего инфракрасного излучения. Отмечено, что особенно широкие возможности открываются при использовании мезопористых пленок из плазмонных наночастиц. Их применение позволяет реализовать динамическое раздельное регулирование пропускания видимого света и ближнего инфракрасного излучения, когда при постепенном увеличении электрического напряжения на стекле последовательно включающиеся механизмы плазмонного и поляронного ослабления солнечного излучения плавно меняют состояние стекла от светлого теплого к светлому холодному и затем к темному холодному.

DOI: $10.21883 /$ OS.2018.04.45759.240-17

\section{Введение}

Окно как ограждающая конструкция здания до середины 70-х годов XX века считалось самым слабым элементом, и его свойства ограничивались значениями светопропускания и сопротивления теплопередаче. Революционные технологии производства стекол с низкоэмиссионными покрытиями в 80-90-х годах XX века придали им новые солнце- и теплозащитные свойства. Окна с такими свойствами открыли эру стеклянной архитектуры. Основу для этого обеспечили три прорыва в области производства светопрозрачных конструкций в прошлом веке:

1) разработка в течение 1950-х годов технологии изготовления флоат-стекла и последующий всеобщий переход производства листового стекла на эту технологию;

2) разработка стеклопакетов и профилей из поливинилхлорида в 1950-60-е годы с последующим массовым их производством;

3) освоение в 1980-90-х годах промышленного производства листового стекла большого размера с теплои солнцезащитными покрытиями.

Формирующаяся в настоящее время концепция „окно будущего“ рассматривает его не как статичный кусок стекла в стене, а как многофункциональное устройство с переменными оптическими и теплотехническими свойствами для поддержания микроклимата здания. Эти свойства могут изменяться в соответствии с изменением погодных условий согласно предпочтению находящихся в здании людей или автоматически с учетом показаний инженерных систем здания. Окно должно стать интеллектуальным элементом конструкции здания, учитывать меняющиеся в течение суток (день, ночь) и времени года (лето, зима) требования к его теплотехническим, светопропускательным и другим показателям.

Речь идет об окнах нового поколения, к которым относятся так называемые умные окна (smart windows). Другие названия - динамические, интеллектуальные или переключаемые окна. В настоящее время на коммерческой основе выпускается следующие виды умных стекол: электрохромные, термохромные, термотропные и ламинированные стекла с двумя видами полимерных пленок - пленки с диспергированными в полимере микрокаплями жидких кристаллов (пленки PDLC polymer dispersed liquid crystals) и пленки с диспергированными в полимере микрокаплями жидкости с взвешенными частицами (пленки SPD - suspended particles devices). Подробно история развития исследований, освоения производства и характеристики различных видов коммерческих умных окон изложены в обзорных работах $[1,2]$.

Из всех видов умных стекол лучшими динамическими свойствами обладают электрохромные стекла. Основной недостаток - одновременное ослабление видимого света и излучения ближнего инфракрасного диапазона (БИК).

В работе приведены результаты выполненных в последние годы исследований в направлении разработки стекол с раздельным регулированием пропускания видимого света и БИК излучения. 


\section{Взаимодействие стекла с излучением}

На внешней поверхности стекла падающее солнечное излучение частично отражается и частично проходит внутрь стекла (рис. 1). При прохождении через стекло излучение испытывает многократные внутренние отражения и частично поглощается, остаток излучения выходит через внутреннюю поверхность. При этом выполняется соотношение

$$
\tau_{\lambda}+\rho_{\lambda}+\alpha_{\lambda}=1
$$

где $\tau_{\lambda}, \rho_{\lambda}, \alpha_{\lambda}-$ соответственно коэффициенты пропускания, отражения и поглощения, зависящие от длины волны.

Все поглощенное излучение преобразуется в теплоту, которая конвекцией и излучением передается от обеих поверхностей стекла.

Спектр солнечного излучения на подходе к внешней поверхности атмосферы близок к описываемому законом Планка спектру черного тела при температуре около $5500^{\circ} \mathrm{C}$. Вследствие поглощения части излучения при прохождении его через атмосферу образуются острые провалы из-за селективного поглощения излучения озоном, кислородом, водяным паром и углекислым газом (рис. 2).

В диапазоне от 0.3 до $3.5 \mu \mathrm{m}$ заключено 99\% энергии солнечного излучения. Весь диапазон солнечного излучения делят на три части:

- ультрафиолетовое (УФ) излучение с длиной волны в диапазоне $0.3<\lambda<0.38 \mu \mathrm{m}$, в котором заключено $5 \%$ энергии солнечного излучения;

- видимый свет $0.38<\lambda<0.78 \mu \mathrm{m}$ содержит 40\% солнечной энергии;

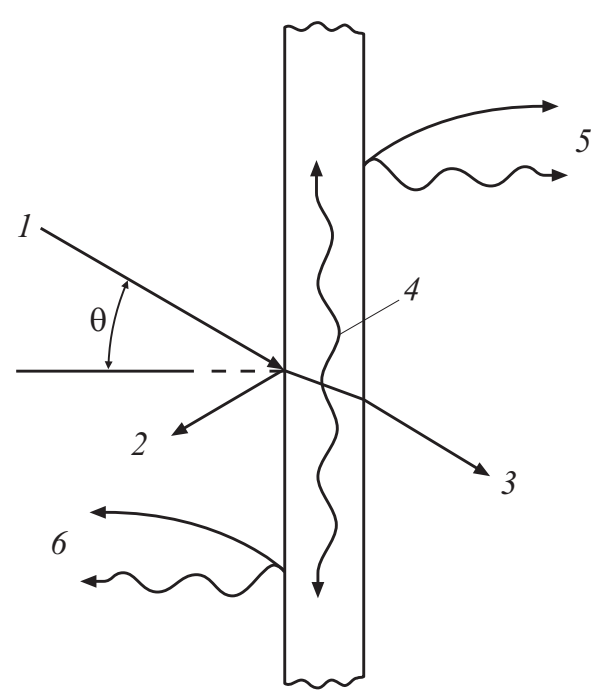

Рис. 1. Взаимодействие солнечного излучения со стеклом: 1 - падающее солнечное излучение, 2 - отраженное излучение, 3 - пропускаемое солнечное излучение, $4-$ поглощенное солнечное излучение, 5 - передача конвекцией и тепловым излучением внутрь помещения теплоты, полученной в результате преобразования в теплоту поглощенного солнечного излучения; 6 - то же, наружу.

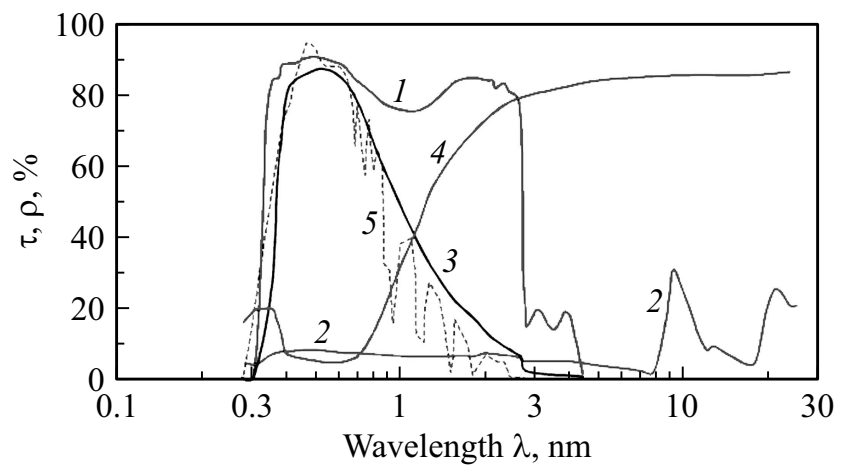

Pис. 2. Спектральные характеристики бесцветного стекла $(1,2)$ и стекла с мягким низкоэмиссионным покрытием $(3,4)$ в сравнении со спектром солнечного излучения [3]: 1 - спектр пропускания $\tau$ бесцветного стекла, 2 - спектр отражения $\rho$ бесцветного стекла, 3 - спектр пропускания $\tau$ стекла с низкоэмиссионным покрытием, $4-$ спектр отражения $\rho$ стекла с низкоэмиссионным покрытием, 5 - спектр солнечного излучения на земной поверхности.

- БИК излучение $0.78<\lambda<3.5 \mu \mathrm{m}$ включает $55 \%$ солнечной энергии.

Спектр излучения тел при температурах, близких к комнатной, расположен в диапазоне $3.5<\lambda<50 \mu \mathrm{m}$, называемом дальним инфракрасным или тепловым излучением. Максимум интенсивности такого излучения соответствует длине волны около $10 \mu \mathrm{m}$.

Соотношение между величинами $\tau_{\lambda}, \rho_{\lambda}, \alpha_{\lambda}$ существенно изменяется в зависимости от длины волны $\lambda$ падающего излучения. Нужно отметить также, что для направленного солнечного излучения это соотношение изменяется также и при изменении угла падения $\theta$. Поэтому обычно все справочные данные для стекол по величинам $\tau_{\lambda}, \rho_{\lambda}, \alpha_{\lambda}$ для различных диапазонов солнечного излучения приводятся для варианта, падающего по нормали к поверхности стекла излучения: $\theta=0^{\circ}$.

На рис. 2 приведены такие характеристики для бесцветного стекла и такого же стекла с мягким низкоэмиссионным покрытием.

Для характеристики стекол часто используют оптические характеристики, усредненные по отдельным диапазонам солнечного излучения (ультрафиолет, видимый свет, ближнее и дальнее инфракрасное излучение) или по всему диапазону солнечного излучения. При этом используют соответствующие нижние индексы. Например, коэффициент пропускания: УФ (UV) излучения $\tau_{\mathrm{UV}}$, видимого света $\tau_{\text {vis }}$, БИК излучения $\tau_{\mathrm{NIR}}$ и всего солнечного излучения $\tau_{\mathrm{s}}$.

\section{Статические стекла с неизменными оптическими свойствами}

\section{Бесцветное флоат-стекло}

Бесцветное флоат-стекло - основа для изготовления всех остальных видов стекол. Его спектральные характе- 
ристики изображены на рис. 2, кривые 1 и 2. Бесцветное стекло хорошо пропускает все солнечное излучение, кроме самой коротковолновой части ультрафиолетового. Но для длин волн более $2 \mu \mathrm{m}$ пропускание стекла резко уменьшается, и для теплового излучения с длиной волны более $4 \mu \mathrm{m}$ бесцветное стекло совершенно непрозрачно: $\tau_{\lambda}(\lambda>4 \mu \mathrm{m})=0$. Для этих условий из выражения (1) следует

$$
\rho_{\lambda}+\alpha_{\lambda}=1 \text {. }
$$

Учитывая закон Кирхгофа $\varepsilon_{\lambda}=\alpha_{\lambda}$, получаем

$$
\varepsilon_{\lambda}=1-\rho_{\lambda} .
$$

Отсюда следует, что спектральный коэффициент эмиссии стекла $\varepsilon_{\lambda}$ для теплового излучения может быть рассчитан по измерениям спектрального коэффициента отражения $\rho_{\lambda}$. На рис. 2 такая зависимость 2 имеет резко изменяющийся вид в области теплового излучения $\lambda>4 \mu \mathrm{m}$. Поэтому используют усредненное значение $\bar{\rho}$, полученное по результатам измерения в 30 точках в диапазоне от 5 до $50 \mu \mathrm{m}$. Величину $\varepsilon=1-\bar{\rho}$ называют коэффициентом эмиссии (в отечественной литературе по теплообмену - степень черноты). Для бесцветного оконного стекла $\varepsilon=0.837$. Такое стекло является черным, не прозрачным для теплового излучения, поскольку оно практически полностью его поглощает. Но такое стекло зимой прозрачно для падающего на него из помещения теплового излучения вследствие последующего его переизлучения наружу.

Для бесцветного флоат-стекла толщиной $3 \mathrm{~mm}$ усредненные по всему диапазону солнечного излучения коэффициенты имеют значения: $\tau_{\mathrm{s}}=0.837, \rho_{\mathrm{s}}=0.075$, $\alpha_{\mathrm{s}}=0.088$.

\section{Теплозащитные стекла}

Нанесение низкоэмиссионного покрытия на бесцветное стекло приводит к снижению пропускательной способности за счет увеличения его отражательной способности по мере увеличения длины волны в области БИК излучения. Спектральные пропускательная $\tau_{\lambda}$ и отражательная $\rho_{\lambda}$ характеристики стекла с таким покрытием изображены в виде кривых 3 и 4 на рис. 2. Высокой отражательной способностью низкоэмиссионного покрытия в области теплового излучения при $\lambda>3.5 \mu \mathrm{m}$ обусловлена низкая излучательная способность $\varepsilon=1-\bar{\rho}$ стекол с таким покрытием.

В настоящее время в подавляющем большинстве случаев используется мягкое низкоэмиссионное покрытие, которое наносится на готовое флоат-стекло вакуумным магнетронным напылением [3-5]. Покрытие называется мягким, поскольку его прочность меньше прочности стекла. Поэтому такие покрытия размещают на внутренних поверхностях в стеклопакете.

Основу низкоэмиссионного покрытия составляет трехслойная структура, состоящая из слоя серебра, размещенного между двумя слоями содержащих свободные

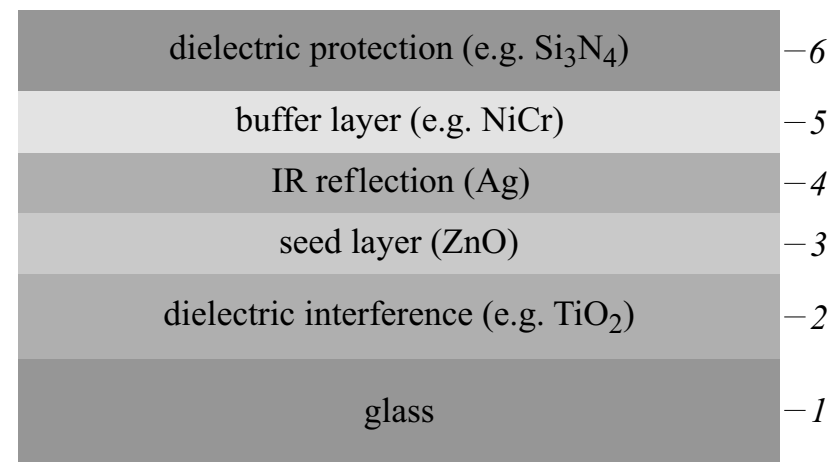

Рис. 3. Пример структуры теплозащитного стекла с содержащим один слой серебра низкоэмиссионным покрытием. 1 - стекло, 2 - диэлектрический интерференционный слой $\left(\mathrm{TiO}_{2}\right), 3$ - подложка, способствующая формированию тонкой сплошной (не зернистой) пленки серебра при его напылении $(\mathrm{ZrO}), 4$ - функциональный слой $(\mathrm{Ag}), 5$ - буферный слой $(\mathrm{NiCr}), 6$ - диэлектрический защитный слой $\left(\mathrm{Si}_{3} \mathrm{~N}_{4}\right)$.

электроны полупроводниковых оксидов. Эффект спектрального пропускания видимой и БИК частей солнечного света достигается за счет явления интерференции электромагнитных волн, вызванного наличием свободных электронов в этих трех слоях. Дополнительные слои наносятся для защиты слоя серебра от окисления, улучшения образования серебряной пленки, повышения оптических свойств, стабильности и механической стойкости покрытия $[4,5]$. В конечном итоге покрытие обычно состоит из 5-6 слоев с одним слоем серебра толщиной 10-15 nm при общей толщине покрытия 50-80 nm (рис. 3). Покрытие с одним слоем серебра называется теплозащитным и его в однокамерном стеклопакете наносят на третью поверхность - на внутреннюю поверхность внутреннего стекла. Отдельная серебряная пленка без дополнительных слоев не пропускает видимый свет.

Низкоэмиссионное покрытие с одним слоем серебра практически полностью отражает тепловое излучение $2.5<\lambda<50 \mu \mathrm{m}$. Тем самым сокращаются потери теплоты излучением из помещения через окно в холодный зимний период. Но такое покрытие достаточно хорошо пропускает в помещение БИК излучение с длиной волны $780<\lambda<2500 \mathrm{~nm}$, на долю которого приходится 53\% солнечной энергии.

\section{Солнцезащитные спектрально-селективное стекла}

Для уменьшения поступления через окно солнечного БИК излучения на стекло наносят спектральноселективное низкоэмиссионное покрытие. Его изготавливают нанесением дополнительных второго и третьего слоев серебра вместе со вспомогательными слоями. Увеличение числа слоев серебра снижает поступление БИК излучения с длиной волны $780<\lambda<2500 \mathrm{~nm}$ (рис. 4). 
Но при этом каждый слой серебра снижает светопропускание примерно на 10\%. Спектрально-селективные покрытия с двумя или тремя слоями серебра называют солнцезащитными и размещают на второй поверхности стеклопакета - на внутренней поверхности внешнего стекла.

Нужно отметить, что промышленная технология вакуумного магнетронного напыления таких покрытий на стекла оконного формата была отработана совсем недавно - в 1990-е годы [3-5].

На рис. 5 приведены примеры спектров пропускания изготавливаемых в России стекол с низкоэмиссионными покрытиями.

Спектрально-селективные солнцезащитные покрытия обладают прекрасными светотехническими свойствами, но у них имеются серьезные недостатки:

- их стоимость высока;

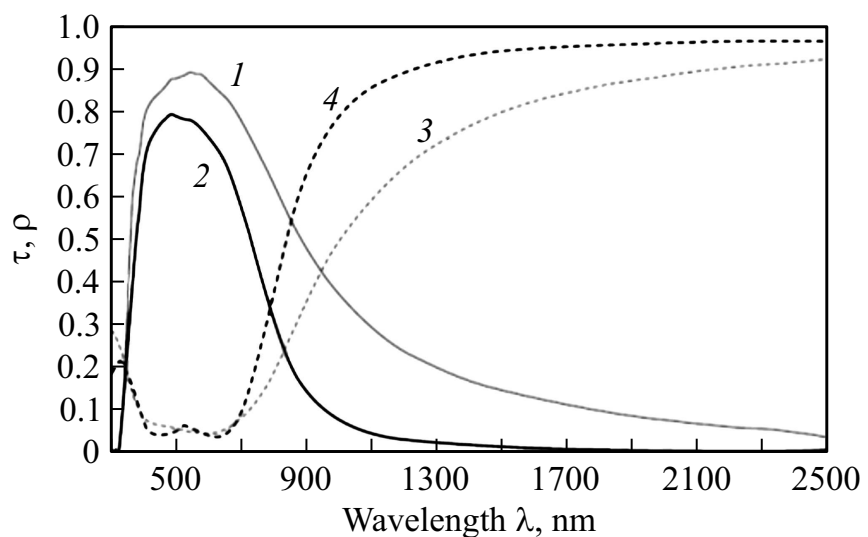

Рис. 4. Спектры пропускания $(1,2)$ и отражения $(3,4)$ стекол с низкоэмиссионными покрытиями компании Saint Gobain теплозащитного с одним $(1,3)$ и солнцезащитного спектральноселективного с двумя $(2,4)$ функциональными слоями серебpa [6].

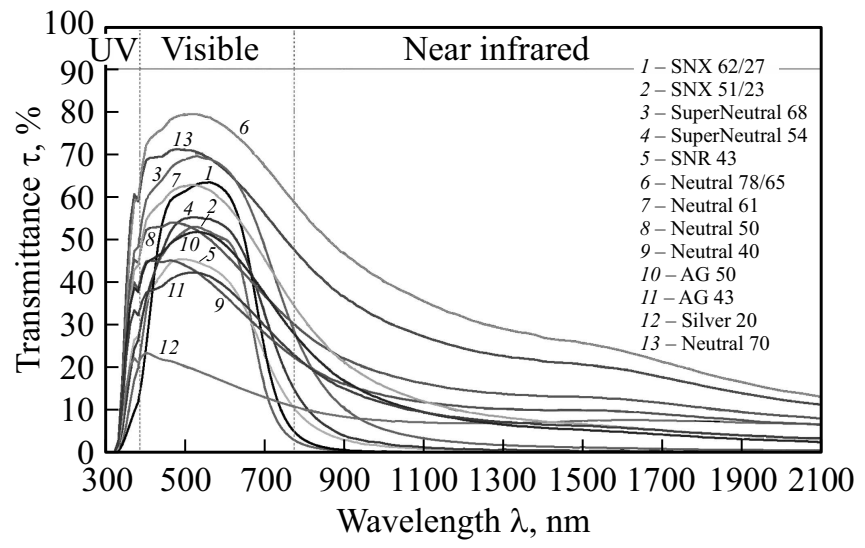

Рис. 5. Спектры пропускания стекол с низкоэмиссионными покрытиями SunGuard [7]. Такие стекла выпускают заводы в г. Рязани и в Ростовской области. $1-S N X$ 62/27; 2 - SNX 51/23; 3 - SuperNeutral 68; 4 - SuperNeutral 54; 5 - SNR 43; 6 - Neutral 78/65; 7 - Neutral 61;8 Neutral 50; $9-$ Neutral 40;10-AG 50;11-AG 43; 12 - Silver 20; 13 - Neutral 70.
- они не пропускают солнечное БИК излучение внутрь помещения зимой;

- они не пропускают (отражают) электромагнитное излучение с длиной волны больше $1 \mu \mathrm{m}$. В этот диапазон попадают и радиоволны. В настоящее время, когда практически каждый человек пользуется мобильным устройством, экранирование радиосвязи окнами является серьезным недостатком.

\section{Статические инфракрасные фильтры с диспергированными плазмонными наночастицами}

Начало XXI века ознаменовалось успехами в области технологии изготовления наночастиц (частицы размером 5-100 nm) и исследования их свойств. При этом были выявлены удивительные оптические свойства этих частиц, а именно способность селективно и контролируемо взаимодействовать со светом, причем эта способность изменяется в зависимости от диапазона излучения и размеров наночастиц [8-10]. Появилась возможность изготавливать материалы, которые могут поглощать излучение нежелательного диапазона, выборочно пропускать или отражать нужные части спектра падающего излучения.

В металлах имеются свободные проводящие электроны, образующие электронный газ (облако) высокой плотности. Плотность электронов в золоте $(\mathrm{Au})$ $5.9 \cdot 10^{22}$, в серебре $(\mathrm{Ag})-5.76 \cdot 10^{22} \mathrm{~cm}^{-3}$. В наночастицах таких материалов свободные электроны могут совершать коллективные колебания под воздействием внешнего электромагнитного поля.

Частота собственных коллективных колебаний свободных электронов за счет электростатических сил называется плазменной частотой $\omega_{\mathrm{p}}$ или частотой объемного плазмона и определяется из соотношения

$$
\omega_{\mathrm{p}}=\left(n e^{2} / m^{*} \varepsilon_{0}\right)^{1 / 2} .
$$

Здесь $n-$ концентрация свободных электронов, $e-$ заряд электрона; $m^{*}$ - эффективная масса электрона внутри наночастицы; $\varepsilon_{0}$ - диэлектрическая проницаемость вакуума. Плазменная частота является важнейшей характеристикой оптических свойств металла.

Свет с частотой ниже плазменной частоты от металлической поверхности отражается, потому что электроны в металле экранируют электрическое поле световой электромагнитной волны. В большинстве металлов плазменная частота находится в УФ области спектра, делая их отражающими (блестящими) в видимом диапазоне, а также непрозрачными для инфракрасного, в частности теплового, излучения и для радиоволн.

Локализованный плазмон - коллективное возбуждение электронного газа и колебаний электромагнитного поля, сосредоточенных в металлических наночастицах (рис. 6). Локализованный плазмон возможен только в наночастицах, размеры которых значительно меньше (не менее чем примерно в 5 раз) длины волны $\lambda$ падающего 


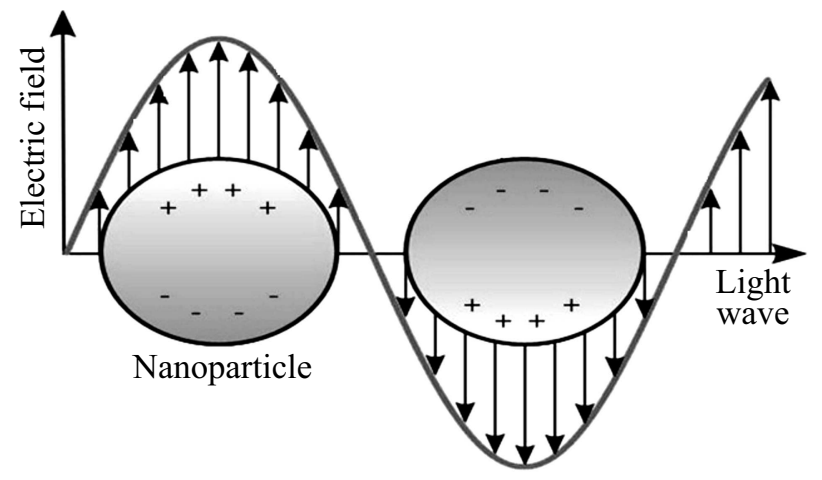

Pис. 6. Схема локализованного плазмона в металлических наночастицах. Переменное электрическое поле световой волны периодически вытесняет облако свободных электронов к поверхности частицы, которые затем испытывают восстанавливающее воздействие со стороны кристаллической решетки положительно заряженных ионов.

электромагнитного излучения. Такие наночастицы называют плазмонными.

Частота плазмона $\omega_{\mathrm{lp}}$ (плазмонная частота), локализованного в металлической наночастице, зависит от ее формы и размеров и обычно меньше плазменной частоты $\omega_{\mathrm{p}}$.

Когда частота внешнего электромагнитного излучения приближается к частоте $\omega_{\text {lp }}$ плазмона, наступает явление локализованного плазмонного резонанса (ЛПР). Частота ЛПР $\omega_{\text {lp }}$ и плазменная частота $\omega_{\text {p }}$ отличаются. Между их величинами выполняется следующее соотношение:

$$
\omega_{\mathrm{lp}}=\left[\omega_{p}^{2} /\left(1+2 \varepsilon_{m}\right)-\gamma^{2}\right]^{1 / 2} .
$$

Здесь $\varepsilon_{m}$ - диэлектрическая постоянная окружающей среды; $\gamma$ - параметр затухания, пропорционален частоте столкновений свободных электронов. Отсюда следует, что на величину частоты ЛПР значительное влияние оказывают также свойства окружающей среды, а именно диэлектрическая постоянная $\varepsilon_{m}$.

Соотношение (5) справедливо для сферических частиц. Свойства локализованных плазмонов критически зависят от формы наночастиц, что позволяет настраивать систему их резонансов на эффективное взаимодействие со светом. При резонансе происходит резкое увеличение поглощения энергии падающего излучения и преобразование ее в энергию колебаний электронного облака. Поглощенное излучение затем абсорбируется или рассеивается. Эти процессы зависят от размеров и свойств частицы, длины волны излучения и свойств окружающей среды.

При локализованном плазмонном резонансе напряженность локального электрического поля на поверхности частицы может в десятки раз превышать напряженность падающего поля. Электрическое поле высокой интенсивности внутри частицы приводит к эффекту резонансного поглощения в металле и к интенсивному нагреву частицы [11].
Вначале использовались металлические наночастицы (серебро, золото) [8]. Концентрация электронов в различных металлах примерно одинакова $\left(\sim 5-6 \cdot 10^{22} \mathrm{~cm}^{-3}\right)$, поэтому в большинстве металлов плазменная частота находится в УФ области спектра. Легирование металлами не проводящих электричество материалов позволяет изменять концентрацию электронов в них на уровне $10^{18}-10^{22} \mathrm{~cm}^{-3}$ и тем самым настраивать частоту их локализованного плазмонного резонанса в соответствии с соотношением (4) в диапазоне от видимого света до ИК. Такие свойства и значительно меньшая стоимость наночастиц из легированных металлических оксидов обусловили чрезвычайно быстрое развитие исследований их свойств и методов изготовления. Список публикаций за последние 10 лет по этой тематике содержит более 350 наименований $[9,10]$.

В период с 1995 по 2007 гг. появились первые десять публикаций с результатами исследований и предложениями по использованию дисперсий наночастиц легированных оксидов в качестве ИК фильтров [12]. Основополагающие результаты были получены сотрудниками японской компании Sumitomo Metal Mining Co., Ltd. (SMM) [12,13]. Предполагалось, что инфракрасные фильтры с дисперсиями наночастиц будут иметь стоимость значительно ниже, чем стекла с низкоэмиссионными покрытиями, нанесенными вакуумным магнетронным способом.

Были выполнены исследования оптических свойств наночастиц из различных материалов (ITO - Indium Tin Oxide - легированный оловом оксид индия $\mathrm{In}_{2} \mathrm{O}_{3}: \mathrm{Sn}, A T O$ - Antimony doped Tin Oxide — легированный сурьмой оксид олова $\mathrm{SnO}_{2}: \mathrm{Sb}, A Z O$ Aluminum doped Zinc Oxide - легированный алюминием оксид цинка $\mathrm{ZnO}: \mathrm{Al}$, редкоземельные гексабориды $\mathrm{LaB}_{6}$, восстановленные оксиды вольфрама $\mathrm{WO}_{2.72}$ и $\left.\mathrm{WO}_{2.83}\right)$. На рис. 7 приведены нормализованные спектры оптического ослабления дисперсий наночастиц металлов и легированных оксидов металлов в прозрачных

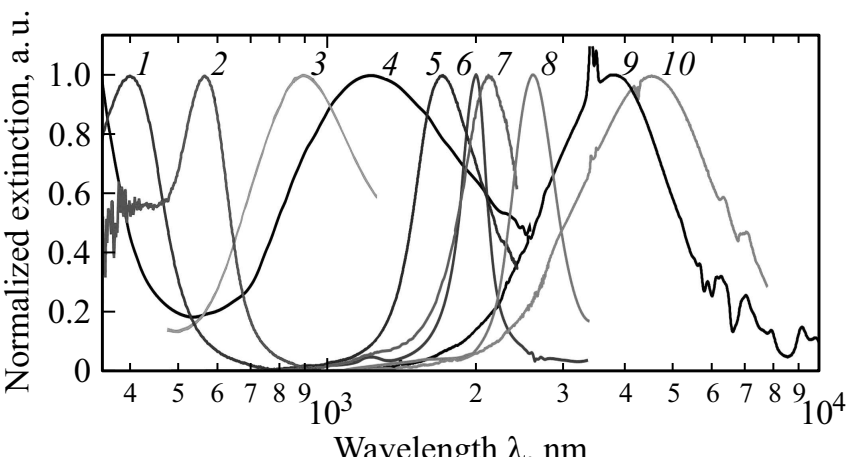

Рис. 7. Нормализованные спектры оптического ослабления дисперсий плазмонных наночастиц в растворах и полимерных пленках [14]. $1-\mathrm{Ag} ; 2-\mathrm{Au} ; 3-\mathrm{WO}_{2,83} ; 4-$ $\mathrm{Cs}_{x} \mathrm{WO}_{3} ; 5-$ ITO $(16.8 \% \mathrm{Sn}) ; 6-I C O-$ Indium doped Cadmium Oxide - легированный индием оксид кадмия $\mathrm{CdO}: \mathrm{In}$ $(16.2 \% \mathrm{In}) ; 7-$ ITO $(4.4 \% \mathrm{Sn}) ; 8-$ ICO $(1.5 \% \mathrm{In}) ; 9-A Z O$ $(5.5 \% \mathrm{Al}) ; 10-A Z O(3.5 \% \mathrm{Al})$. 
растворах и полимерных пленках. Дисперсии частиц, как и отдельные частицы, ослабляют проходящее излучение в узком диапазоне около резонансной частоты. Положение максимума полосы ослабления соответствует резонансной частоте, в основном определяется концентрацией свободных электронов и сдвигается влево по мере ее увеличения. Здесь следует отметить значительно превышающую остальные ширину полосы ослабления вольфрамовой оксидной бронзы $\mathrm{Cz}_{x} \mathrm{WO}_{3}$ и положение ее максимума.

В ходе исследований и сравнений было установлено, что наилучшими свойствами обладают вольфрамовые оксидные бронзы $\left(\mathrm{M}_{x} \mathrm{WO}_{3}\right)$. Эти материалы получаются при легировании триоксида вольфрама $\mathrm{WO}_{3}$ щелочными металлами $\mathrm{Li}, \mathrm{Na}, \mathrm{K}, \mathrm{Cs}, \mathrm{Rb}$, а также ионами $\mathrm{NH}_{4}^{+}$. По сравнению с остальными материалами дисперсии наночастиц вольфрамовых оксидных бронз показали наилучшее пропускание видимого света и наилучшие свойства по защите от БИК излучения. В последние годы разработаны экономичные способы получения наночастиц вольфрамовых оксидных бронз однородного фракционного состава путем синтеза в растворе при сверхкритических давлении и температуре.

За счет изменения концентрации легирующих добавок, размеров и формы наночастиц можно в широких пределах изменять и регулировать характер ослабления (рассеивание или поглощение), а также его положение в БИК диапазоне солнечного излучения, где происходит это взаимодействие. Все это открывает чрезвычайно широкие перспективы для использования плазмонных наночастиц при изготовлении спектрально-селективных оптических материалов (ИК фильтров) низкой стоимости.

Наночастицы $\mathrm{Cs}_{0.33} \mathrm{WO}_{3}$ по сравнению с другими легированными оксидами имеют очень широкую полосу поглощения ИК излучения. Объясняется это наличием Двух одновременно действующих механизмов [15]. Основной - плазмонный резонанс с полосой поглощения с центром около $1550 \mathrm{~nm}$. Второй, вспомогательный, поляронный механизм поглощения света с полосой с центром около $880 \mathrm{~nm}$. Свободные электроны, отделяющиеся от инжектируемых внутрь структуры $\mathrm{WO}_{3}$ атомов Cs, локализуются на ионах металла $\mathrm{W}_{i}^{6+}$, уменьшая их заряд до $\mathrm{W}_{i}^{5+}$ и образуя малые поляроны

$$
\mathrm{W}_{i}^{6+}+e^{-}=\mathrm{W}_{i}^{5+} .
$$

Компенсатором возникшего заряда являются катионы $\mathrm{Cs}^{+}$. Поглощая фотоны солнечного света с энергией около $h v \sim 1.4 \mathrm{eV}$, эти электроны получают энергию, достаточную для перехода на соседние ионы $\mathrm{W}_{j}^{6+}$ (межвалентный перенос или перенос поляронов) в соответствии с уравнением

$$
h v+\mathrm{W}_{i}^{5+}+\mathrm{W}_{j}^{6+} \rightarrow \mathrm{W}_{i}^{6+}+\mathrm{W}_{j}^{5+} .
$$

При переходе с атома на атом электроны поглощают фотоны с энергией в широкой полосе спектра с центром

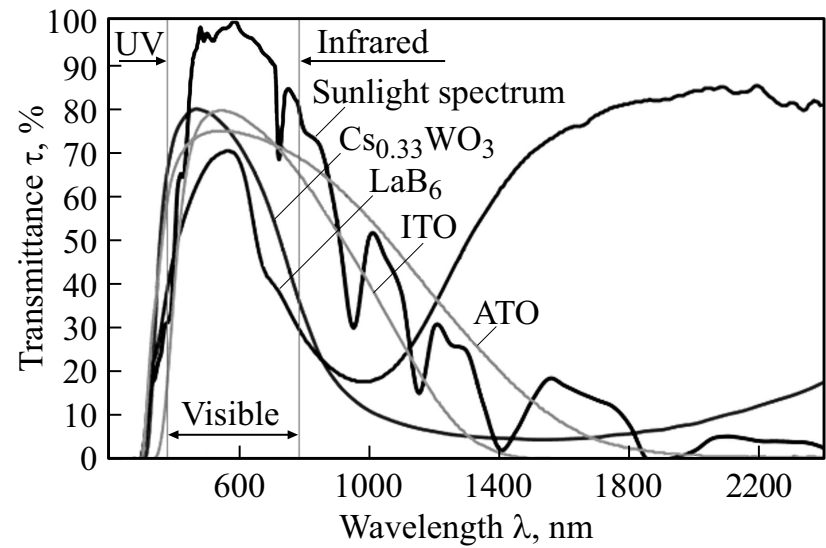

Рис. 8. Спектр солнечного излучения и спектры пропускания дисперсий плазмонных наночастиц [18].

около $880 \mathrm{~nm}$ в области БИК излучения, в том числе частично в диапазоне видимого света от зеленого до красного, что и вызывает окрашивание проходящего через устройство солнечного света в голубой цвет $[16,17]$. При увеличении концентрации инжектированного заряда возрастает интенсивность окраски, при этом происходит сдвиг максимума полосы поглощения в сторону меньших длин волн.

На рис. 8 приведены спектральные характеристики дисперсий наночастиц основных материалов для применения в качестве ИК фильтров. Все они хорошо пропускают видимый свет. Снижение пропускания БИК излучения достигается в основном не за счет его отражения, но за счет поглощения.

Характеристики дисперсий наночастиц ITO, ATO соответствуют оптимальному содержанию легирующих добавок. Для ATO это достигается при весовом содержании сурьмы $\sim 10 \%$. Для ITO оптимальное содержание легирующего олова равно $\sim 10 \%$. Оба эти материала недостаточно хорошо поглощают БИК излучение в диапазоне 800-1400 nm, на который приходится основная (более 75\%) доля энергии БИК солнечного излучения.

Дисперсии $\mathrm{Cs}_{0.33} \mathrm{WO}_{3}$ и $\mathrm{LaB}_{6}$ обладают наилучшими солнцезащитными свойствами. По количеству вещества $\mathrm{Cs}_{0.33} \mathrm{WO}_{3}$ требуется примерно в 10 раз меньше по сравнению с ITO и ATO для достижения одинакового солнцезащитного эффекта. Вещества $\mathrm{LaB}_{6}$ требуется для этих целей еще меньше: примерно в 10 раз меньше, чем $\mathrm{Cs}_{0.33} \mathrm{WO}_{3}$. Но такое уменьшение количества $\mathrm{LaB}_{6}$ приводит к снижению пропускания света и появлению зеленого оттенка (рис. 8).

Разработки светопрозрачных инфракрасных фильтров с плазмонными наночастицами в настоящее время достигли стадии коммерческого продукта. Компания Sumitomo Metal Mining Co., Ltd выпускает два продукта из $\mathrm{Cs}_{0.33} \mathrm{WO}_{3}$ и $\mathrm{LaB}_{6}$ [18]. Порошок полимера с диспергированными наночастицами применяется в качестве добавки при изготовлении ИК фильтров в виде листового пластика или пленок для ламинирования стекол. 
Таблица 1. Оптические свойства существующих и разрабатываемых оконных стекол

\begin{tabular}{|c|c|c|c|c|c|c|}
\hline \multirow{3}{*}{ Стекло } & \multicolumn{5}{|c|}{ Вид излучения и длина волны $\lambda, \mathrm{nm}$} & \multirow{3}{*}{$\begin{array}{c}\text { Начало } \\
\text { производства }\end{array}$} \\
\hline & УФ излучение & Видимый свет & БИК излучение & Тепловое & Радио & \\
\hline & $200-380$ & $380-780$ & $780-3500$ & $3500-50000$ & $>50000$ & \\
\hline
\end{tabular}

Статические стекла с неизменными свойствами

\begin{tabular}{c|c|c|c|c|c|c}
\hline I & $\bullet$ & $\circ$ & $\circ$ & $\circ$ & $\circ$ & - \\
\hline II & $\bullet$ & $\circ$ & $\circ$ & $\bullet$ & $\bullet$ & $1980-$ г годы \\
\hline III & $\bullet$ & $\circ$ & $\bullet$ & $\bullet$ & $\bullet$ & $1990-\mathrm{e} \mathrm{годы}$ \\
\hline IV & $\bullet$ & $\circ$ & $\bullet$ & $\circ$ & $\circ$ & $\sim 2014$ г. \\
\hline
\end{tabular}

Динамические стекла с регулируемыми свойствами

\begin{tabular}{c|c|c|c|c|c|c}
\hline $\mathrm{V}$ & $\bullet$ & \multicolumn{2}{|c|}{ Динамическое одновременное регулирование } & $\bullet$ & $\bullet$ & $\sim 2010$ г. \\
\hline VI & $\bullet$ & $\circ$ & Динамическое регулирование & $\bullet$ & $\bullet$ & R\&D* \\
\hline VII & $\bullet$ & Динамическое регулирование & Динамическое регулирование & $\bullet$ & $\bullet$ & R\&D*
\end{tabular}

Примечание. о - постоянно пропускает излучение в данном диапазоне; • - постоянно не пропускает излучение в данном диапазоне.

I - бесцветное флоат-стекло.

II - теплозащитное стекло с содержащим один слой серебра низкоэмиссионным покрытием.

III - спектрально-селективное солнцезащитное стекло с содержащим два или три слоя серебра низкоэмиссионным покрытием.

IV - статические ИК фильтры с диспергированными плазмонными наночастицами.

$\mathrm{V}$ - динамические регулируемые электрохромные стекла.

VI - динамические регулируемые ИК фильтры с диспергированными плазмонными наночастицами.

VII - динамические регулируемые двухполосные стекла - фильтры видимого света и БИК излучения.

* Research and Development.

Компания Fujifilm Co. Ltd выпускает дисперсии наночастиц $\mathrm{Cs}_{0.33} \mathrm{WO}_{3}$ [19], а также пленки с серебряными нанодисками „Nano Silver Pavement (NASIP)“ [20,21]. В такой пленке серебряные нанодиски толщиной $11 \mathrm{~nm}$ и средним эквивалентным диаметром $120 \mathrm{~nm}$ диспергированы в плоскости в один слой и занимают около $40 \%$ поверхности. Отличительная черта пленки с нанодисками состоит в том, что она ослабляет проходящее БИК излучение в основном за счет его отражения, а не поглощения, как это делают пленки с дисперсиями наночастиц произвольной формы.

Более подробный анализ истории развития технологии изготовления, исследований оптических свойств и описание характеристик коммерческих продуктов дисперсий плазмонных наночастиц и способов из применения для изготовления инфракрасных фильтров изложены в обзорной работе [22].

Светопрозрачные конструкции с поглощающими БИК излучение фильтрами на основе дисперсии плазмонных наночастиц из легированных оксидных материалов обладают рядом преимуществ:

- высокое светопропускание в сочетании с низким поступлением солнечной теплоты;

- прозрачность для радиоволн;

- высокая стабильность и низкая стоимость.

Спектральные характеристики и время начала изготовления на коммерческой основе оконных стекол различных видов приведены в табл. 1.

\section{Динамические стекла с регулируемыми оптическими свойствами}

\section{Электрохромные стекла}

В электрохромных стеклах регулирование интенсивности проходящего через них солнечного излучения осуществляется за счет изменения постоянного электрического напряжения.

Схема электрохромного устройства изображена на рис. 9. Устройство состоит из пятислойной электрохимической ячейки 2-5, закрепленной на прозрачной подложке 1. В другом варианте ячейка расположена между двумя подложками 1 и 6 в виде ламинированной конфигурации. Прозрачные подложки - обычно стекла, но также могут быть и гибкой полимерной пленкой. В коммерческих электрохромных стеклах используется твердый или полимерный электролит. При этом толщина пятислойной структуры в первом случае около $1 \mu \mathrm{m}$, во втором - около $0.75 \mathrm{~mm}$.

Центральная часть 4 электрохимической ячейки проводник ионов (электролит) - может состоять из органического материала (клейкий полимер) или неорганического соединения (обычно оксидная пленка). Ионы обычно имеют малый размер для того, чтобы сохранять подвижность: протоны $\mathrm{H}^{+}$или $\mathrm{Li}^{+}$. Проводник ионов не должен проводить электроны и находится в контакте с электрохромным слоем 3 (наиболее часто применяется $\left.\mathrm{WO}_{3}\right)$, который обладает смешанной проводимостью и 


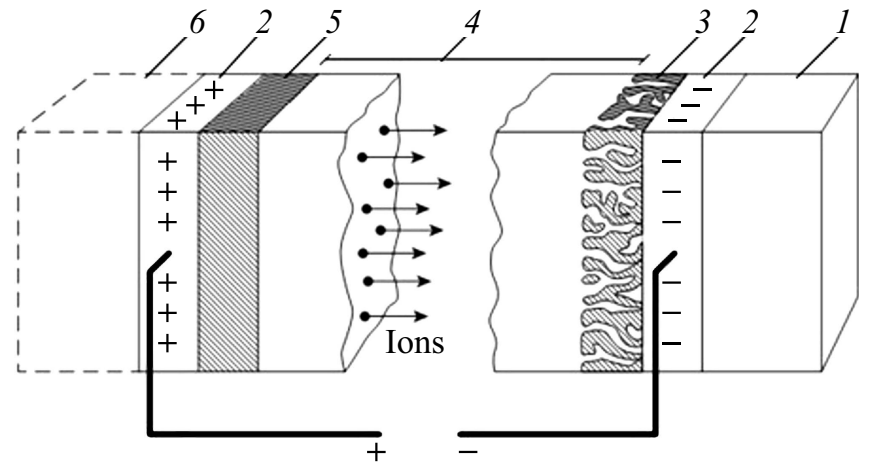

Рис. 9. Схема электрохромного устройства [23]: 1 - прозрачная подложка из стекла или гибкой полимерной пленки, 2 - прозрачный электропроводящий слой, 3 - электрохромный слой, 4 - проводник ионов - электролит, 5 - источник ионов или электрохромный слой, $6-$ прозрачная подложка из стекла или гибкой полимерной пленки или ее отсутствие (штриховое изображение).

хорошо проводит как ионы, так и электроны. Другой поверхностью проводник ионов контактирует со слоем 5, выполняющим функцию источника ионов. Идеальный вариант - если этот слой 5 одновременно выполняет функцию электрохромного слоя, комплементарного к первому слою 3. Эта центральная трехслойная структуpa 3-5 расположена между двумя прозрачными электропроводящими покрытиями 2. Покрытия обладают только электронной проводимостью. Следует отметить, что прозрачные электропроводящие покрытия являются наиболее дорогостоящим элементом электрохромных изделий.

Когда постоянное напряжение около одного вольта прикладывается между электропроводящими покрытиями 2, ионы инжектируются из источника ионов 5 в электрохромный слой 3. Электроны инжектируют в электрохромный слой 3 из электропроводящего покрытия. Электроны вызывают изменение оптического поглощения - окрашивание этого слоя. Дополнительный эффект достигается в идеальном варианте, когда при экстракции ионов окрашивается и слой 5 , который в этом случае выполняет функцию не только источника ионов, но также и функцию электрохромного слоя.

Изменение полярности напряжения возвращает устройство в исходное состояние. Степень затемнения может быть зафиксирована на любом промежуточном уровне и длительное время оставаться неизменной без электрического тока в цепи - „эффект памяти“. Это означает, что изменение оптического состояния происходит только при движении зарядов (при наличии электрического тока).

В настоящее время в качестве катодного электрохромного материала во всех коммерческих изделиях применяется триоксид вольфрама $\mathrm{WO}_{3}$. Суть электрохромного эффекта состоит в том, что при двойной инжекции в пленку триоксида вольфрама легких ионов $\left(\mathrm{H}^{+}, \mathrm{Li}^{+}\right.$, $\mathrm{Na}^{+}, \mathrm{K}^{+}$) и электронов она окрашивается в голубой цвет.
Процессы окрашивания (в голубой цвет, на схеме (8) слева направо) и обесцвечивания (справа налево) связаны с химической реакцией образования соединения с переменным составом:

$$
\left[\mathrm{WO}_{3}+x \mathrm{M}^{+}+x e^{-}\right] \leftrightarrow\left[\mathrm{M}_{x} \mathrm{WO}_{3}\right]
$$

где $\mathrm{M}^{+}$может быть $\mathrm{H}^{+}, \mathrm{Li}^{+}, \mathrm{Na}^{+}, \mathrm{K}^{+} ; e^{-}$- электрон; $x$ - стехиометрический коэффициент, изменяющийся в диапазоне $0 \div 1$.

Электроны, инжектируемые внутрь структуры $\mathrm{WO}_{3}$ вместе с ионами, обеспечивают описанный ранее выражениями (6), (7) поляронный механизм поглощения света в широкой полосе спектра с центром около $880 \mathrm{~nm}$ в области БИК излучения, в том числе частично в диапазоне видимого света от зеленого до красного, что и вызывает окрашивание проходящего через устройство солнечного света в голубой цвет. Причем при увеличении концентрации инжектированного заряда возрастает интенсивность окраски, при этом происходит сдвиг максимума полосы поглощения в сторону меньших длин волн. При экстракции заряда пленка возвращается в прозрачное неокрашенное состояние.

На рис. 10 изображены спектры пропускания $\tau_{\lambda}$ электрохромного стекла в крайних прозрачном и затененном состояниях. При увеличении напряжения имеет место плавный переход от кривых 1, 2 к кривым 3, 4. Основной недостаток (помимо высокой стоимости) электрохромных стекол - при увеличении напряжения они ослабляют видимый свет и БИК излучение одновременно, не раздельно.

Более подробный анализ истории развития технологии изготовления, описание оптических свойств и характеристик коммерческих электрохромных стекол выполнен в обзорных работах $[1,2]$.

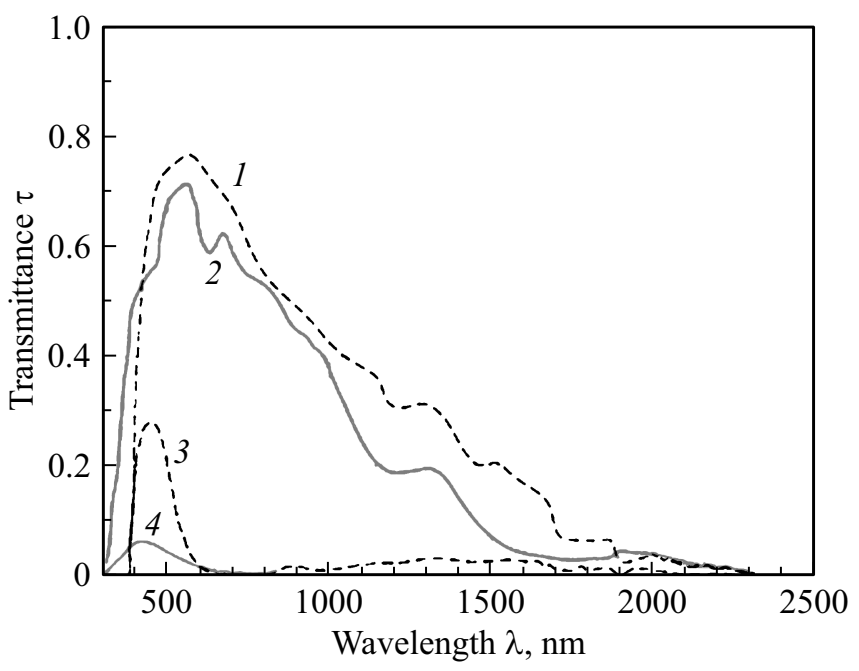

Рис. 10. Спектры пропускания коммерческих электрохромных стекол в прозрачном состоянии $(1,2)$ при отсутствии и в затемненном состоянии $(3,4)$ при подключении электрического напряжения [2]. Штриховые линии 1,3- стекло Gesimat EC, сплошные линии 2,4- стекло SageGlass. 
Раздельное регулирование пропускания видимого света и БИК излучения - весьма сложная задача. При этом регулирование пропускания БИК излучения - это отдельная составная ее часть.

\section{Динамические инфракрасные фильтры с диспергированными плазмонными наночастицами}

За счет изменения концентрации легирующих добавок, размеров и формы наночастиц можно в широких пределах изменять и регулировать характер ослабления (рассеивание или поглощение), а также его положение в БИК диапазоне солнечного излучения, где происходит это взаимодействие. Однако после диспергирования плазмонных наночастиц в прозрачном материале получающийся ИК фильтр обладает неизменными свойствами, блокируя БИК солнечное излучение и летом, и зимой. Это хорошо в странах с теплым климатом, и плохо в странах с умеренным климатом, где зимой проходящее сквозь окна солнечное БИК излучение нагревает помещения.

Динамическое изменение полосы ослабления БИК излучения плазмонных наночастиц фиксированного состава можно обеспечить контролируемым изменением концентрации электронов за счет инжекции электронов внутрь наночастиц или их экстракции каким-либо способом. Электрохимический способ внедрения-вывода электронов был найден в начале 2000-х годов [24]. Явление было обнаружено для наночастиц из $\mathrm{Ag}, \mathrm{CdSe}$, $A T O$. Эффект изменения резонансной частоты при инжекции электронов зависит от исходной концентрации электронов в материале: в материалах с высокой концентрацией электронов (металлы) инжекция или удаление даже большого количества электронов приводит к относительно малому изменению их концентрации. Напротив, в материалах с низкой концентрацией электронов при этом достигается существенное относительное изменение их концентрации. Но полосы поглощения наночастиц из таких материалов лежат в дальнем краю БИК диапазона.

Примерно через 10 лет после выявления этого эффекта группой исследователей в США под руководством D.J. Milliron было экспериментально реализовано динамическое электрохимическое модулирование БИК излучения с использованием наночастиц из электропроводящих оксидов ITO и AZO [25,26]. Используемая электрохимическая (электрохромная) ячейка представляет собой слоистую структуру, основными элементами которой являются два стекла с прозрачным электропроводящим оксидным покрытием (обычно ITO или FTO - Fluorine doped Tin Oxide, легированный фтором оксид олова $\left.\mathrm{SnO}_{2}: \mathrm{F}\right)$ и содержащим ионы лития $\mathrm{Li}^{+}$электролитом между ними. На поверхность ITO покрытия наносится тонкий слой плазмонных наночастиц (рис. 11). Структура ячейки выражается формулой: стекло/ITO/слой плазмонных

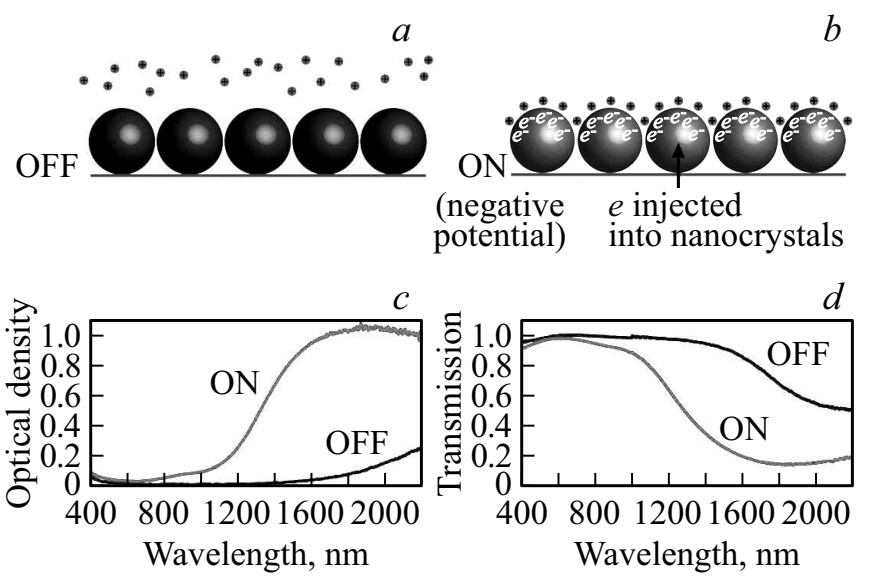

Рис. 11. Схема емкостной природы электрохромного эффекта и вызванное им изменение оптических свойств плазмонных наночастиц [24]. (a) В выключенном (Off) состоянии наночастицы электронейтральны и ионы $\mathrm{Li}^{+}$равномерно распределены по объему электролита. (b) Во включенном (On) состоянии отрицательный потенциал прикладывается к электроду с контактирующими с ним наночастицами. Электроны инжектируются внутрь наночастиц и создают отрицательный заряд. Ионы $\mathrm{Li}^{+}$располагаются около поверхности наночастиц для компенсации заряда наночастиц емкостным (конденсаторным) способом. (c) Оптическая плотность слоя наночастиц возрастает при инжекции электронов. Увеличение концентрации электронов вызывает повышение интенсивности плазмонного резонанса, плотности оптического поглощения и „голубой“ сдвиг полосы поглощения. $(d)$ Соответствующее изменение пропускательной способности слоя наночастиц.

наночастиц/электролит/ITO/стекло. Два слоя ITO выполняют функции электропроводников.

При отсутствии разности потенциалов ионы $\mathrm{Li}^{+}$равномерно распределены по объему электролита. Плазмонные наночастицы находятся в нейтральном состоянии и ослабляют проходящее через электрохимическую ячейку солнечное излучение в соответствии с их исходным фиксированным состоянием.

При подаче отрицательного потенциала на ITO покрытие электроны инжектируются внутрь наночастиц и создают отрицательный заряд. Положительные ионы $\mathrm{Li}^{+}$из электролита под действием электрического поля перемещаются к поверхности наночастиц и нейтрализуют их отрицательный заряд, образуя двойной электрический слой. В результате происходит емкостное (конденсаторное) увеличение концентрации электронов в наночастице. Увеличение концентрации электронов внутри наночастиц приводит к повышению частоты плазмонного резонанса и к „голубому“ сдвигу полосы ослабления проходящего солнечного света. Величина этого сдвига возрастает при увеличении разности потенциалов на ячейке. Для слоя наночастиц ITO размером $4.1 \mathrm{~nm}$ изменение разности потенциалов от 0 до $2.5 \mathrm{~V}$ привело примерно к трехкратному увеличению концентрации свободных электронов в них - от $4.5 \cdot 10^{20}$ 


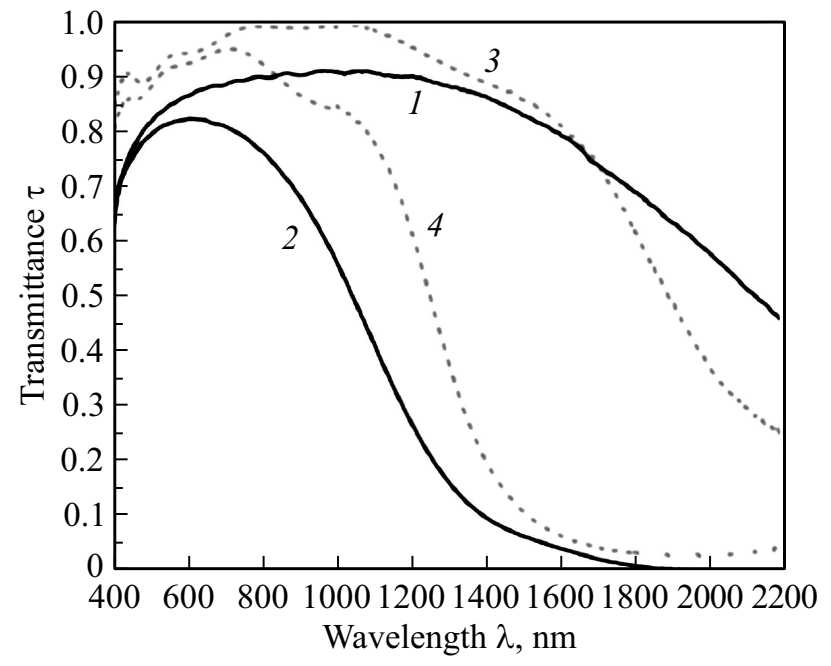

Рис. 12. Изменение спектральных пропускательных свойств нанокристаллических пленок $A Z O(1,2)$ и $\operatorname{ITO}(3,4)$ в процессе электрохромной модуляции в „прозрачном“ $(1,3)$ и „затененном“ $(2,4)$ состояниях [26]. Напряжение в „прозрачном“ и „затененном“состояниях изменяется от 4 до $1.5 \mathrm{~V}$ и от 4 до $2 \mathrm{~V}$ для $A Z O$ и $I T O$ нанокристаллических пленок соответственно. Пленка $A Z O$ имеет толщину $2435 \mathrm{~nm}$, состоит из кристаллов размером $9 \mathrm{~nm}$ при содержании в них $3.7 \%$ легирующего Al. Пленка ITO имеет толщину $316 \mathrm{~nm}$, состоит из кристаллов размером $5 \mathrm{~nm}$ при содержании в них 13.1\% легирующего $\mathrm{Sn}$.

до $14.5 \cdot 10^{20} \mathrm{~cm}^{-3}$ и к почти двукратному уменьшению длины волны максимума полосы ослабления [25].

При отключении разности потенциалов электрохромная ячейка возвращается в исходное состояние. При подаче положительного потенциала на ITO покрытие со слоем плазмонных наночастиц часть свободных электронов удаляется из наночастиц и на них создается положительный заряд. Уменьшение концентрации свободных электронов внутри наночастиц приводит к снижению частоты плазмонного резонанса и к „красному“ сдвигу полосы ослабления проходящего солнечного излучения по сравнению с исходным нейтральным состоянием электрохромной ячейки.

На рис. 12 приведены данные по изменению оптических свойств слоев плазмонных наночастиц двух видов в результате электрохромного модулирования. В ка-

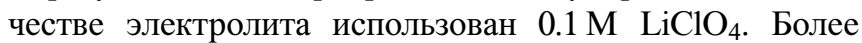
существенное ослабление БИК излучения пленкой $A Z O$ частично объясняется тем, что ее толщина $2435 \mathrm{~nm}$ почти в восемь раз больше толщины $316 \mathrm{~nm}$ пленки ITO.

Интенсивность ослабления излучения определяется емкостью конденсатора - величиной дополнительного заряда, приходящегося на единицу поверхности стекла. Эта величина возрастает при увеличении свободной поверхности наночастиц, доступной для ионов $\mathrm{Li}^{+}$, на которой образуется двойной заряженный слой. Чем больше развита свободная поверхность наночастиц, тем больше количество инжектируемых в наночастицы электронов. Доступная для ионов $\mathrm{Li}^{+}$внутрипоровая поверх- ность возрастает при уменьшении размеров наночастиц и увеличении толщины их слоя.

Значительное влияние на доступность внутрипоровой поверхности пленки оказывает ее структура - характер упаковки наночастиц. При плотной упаковке наночастиц поры между ними и соединяющие их каналы имеют чрезвычайно малые размеры, что значительно затрудняет продвижение ионов $\mathrm{Li}^{+}$к поверхности наночастиц. Для нанокристаллов близкой к сферической формы разработана технология изготовления пленки упорядоченной микроструктуры с мезо- и нанопорами (рис. 13). При среднем размере наночастиц около $4 \mathrm{~nm}$ крупные поры имеют размер от 30 до $37 \mathrm{~nm}$ при общей пористости структуры около 60\%. Толщина пленки 300-400 nm.

Такая организованная структура особенно необходима при использовании пластифицированных полимерных электролитов. Только с полимерными или твердыми электролитами возможно создание электрохромных динамических стекол оконного формата. Полимерный электролит заполняет внутреннее пространство упорядоченной микроструктуры и обеспечивает матрицу для перемещения ионов $\mathrm{Li}^{+}$к поверхности наночастиц.

Первые положительные экспериментальные результаты такого рода создали задел для быстрого развития аналогичных исследований в других странах.

Показательные результаты приведены на рис. 14. Электрохромная ячейка имеет структуру стекло/FTO/ пленка ITO наночастиц/электролит/Pt/FTO/стекло. Электрохромная пленка толщиной $1.1 \mu \mathrm{m}$ изготовлена из ITO наночастиц средним размером $10 \mathrm{~nm}$ и имеет высокопористую регулярную структуру. Концентрация олова в наночастицах 9\%. В качестве электролита использована смесь $1 \mathrm{MLiClO}_{4}+0.005 \mathrm{M} \mathrm{LiI}$, растворенная в смеси пропиленкарбоната и ацетонитрила (70:30). Расстояние между стеклами $25 \mu \mathrm{m}$. Эти результаты интересны тем, что изменение пропускания электрохромной пленки зафиксировано в широком диапазоне изменения $a$

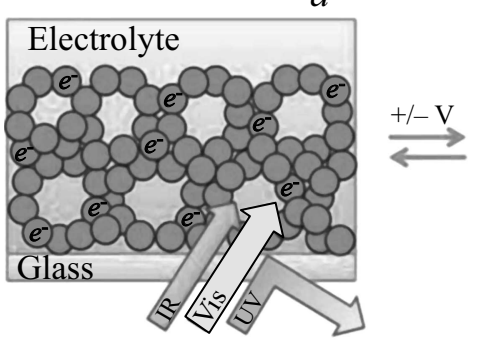

$b$

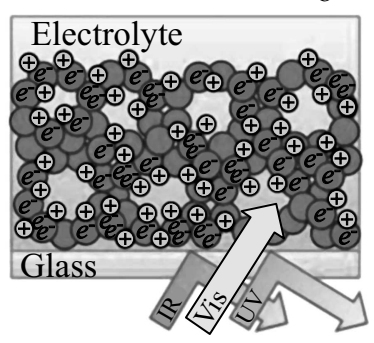

Рис. 13. Нанокристаллическая электрохромная пленка с упорядоченной мезо- и нанопористой структурой [27]. (a) При отсутствии или подаче положительного напряжения пленка пропускает видимый свет (vis) и БИК (NIR) излучение, но ослабляет УФ (UV) излучение. (b) При подаче отрицательного потенциала электроны инжектируются из электрода внутрь нанокристаллов, а ионы $\mathrm{Li}^{+}$из электролита проникают внутрь пористой структуры и располагаются около поверхности нанокристаллов. Пленка пропускает только видимый свет, но ослабляет БИК и УФ излучение. 


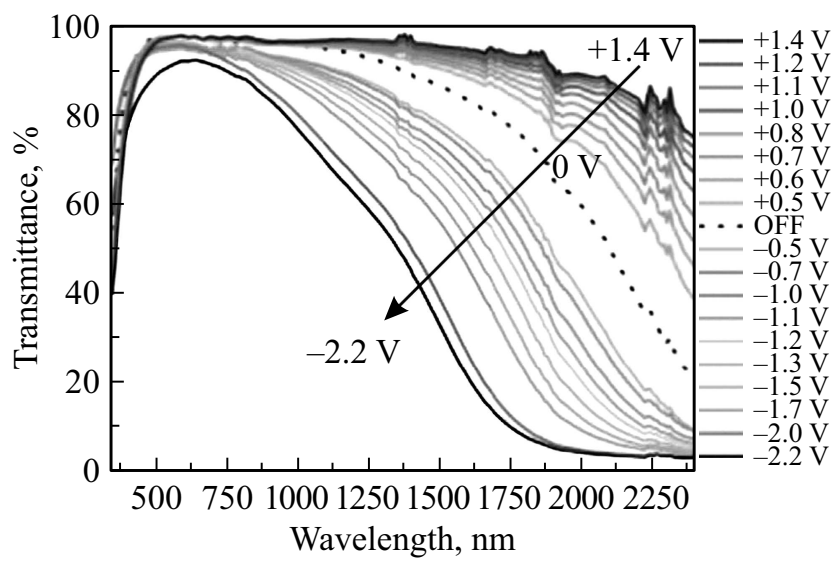

Рис. 14. Изменение спектра пропускания ITO нанокристаллической пленки при изменении напряжения от +1.4 до $-2.2 \mathrm{~V}[28]$.

ее потенциала от исходного нейтрального состояния в обе стороны. При этом особый интерес имеют результаты при увеличении потенциала электрохромной пленки в положительную сторону. В этом случае из наночастиц пленки происходит удаление электронов, явление плазмонного резонанса постепенно ослабевает и уменьшается ослабление проходящего излучения с перемещением полосы ослабления вправо. При потенциале $+1.4 \mathrm{~V}$ электрохромная пленка практически полностью теряет поглощение в области БИК излучения.

При изменении потенциала от нейтрального состояния в сторону отрицательных значений интенсивность ослабления БИК излучения быстро возрастает. При изменении потенциала электрохромной пленки от +1.4 до $-2.2 \mathrm{~V}$ снижение пропускания БИК излучения в диапазоне $780-2500 \mathrm{~nm}$ составляет $\Delta \tau_{\mathrm{NIR}}=38.1 \%$. При этом уменьшение пропускания видимого света очень незначительно $\Delta \tau_{\text {vis }}=4.1 \%$.

Величина снижения пропускания БИК излучения при использовании электрохромной пленки из ITO наночастиц имеет ограниченное значение. Ограничение обусловлено тем, что максимум полосы поглощения исходных ITO наночастиц с концентрацией олова $9 \%$ находится около $1600 \mathrm{~nm}$, тогда как основная часть солнечного БИК излучения (более $75 \%$ ) располагается в диапазоне $780-1400 \mathrm{~nm}$.

Для более эффективного модулирования БИК излучения необходимы материалы с плазмонной резонансной длиной волны в диапазоне 900-1000 nm. Такими материалами являются восстановленные оксиды вольфрама $\mathrm{WO}_{3 x}$ или цезиевая вольфрамовая бронза $\mathrm{Cs}_{0.33} \mathrm{WO}_{3}$.

\section{Электрохромные стекла с раздельным регулированием видимого света и ближнего инфракрасного излучения}

После первых удачных экспериментов по модуляции БИК излучения появилась возможность реализовать более сложную систему по „двухполосному“ раздельному регулированию БИК и видимого излучения. Инициатором снова выступила группа исследователей под руководством D.J. Milliron [29]. Двухполосное модулирование дает возможность использовать окно летом и зимой (в холодном и жарком климате), обеспечивая при этом высокие энергоэффективность и комфорт. При этом были использованы все предыдущие наработки по формированию структурированного высокопористого слоя наночастиц.

Замысел электрохромного раздельного регулирования пропускаемых видимого света и БИК излучения состоит в том, чтобы при постепенном изменении напряжения на электрохромном слое обеспечить последовательное подавление соответствующих участков (полос) солнечного спектра. При этом желательная последовательность такова:

- сначала подавляется БИК излучение, ответственное за поступление теплоты в помещение;

- затем постепенно подавляется видимый свет (затенение) при избыточном интенсивном потоке солнечного излучения.

При этом последовательно реализуются следующие состояния стекла-окна: „светлое теплое (прозрачное) - „светлое холодное“ (блокирование БИК излучения) — „темное холодное“ (блокирование БИК и видимого излучения).

Вначале использовались два различных материала:

- плазмонные наночастицы для динамического регулирования БИК излучения при низком напряжении;

- другие материалы с обычным электрохромным модулированием видимого света за счет поляронного эффекта при инжекции электронов и ионов $\mathrm{Li}^{+}$или $\mathrm{H}^{+}$ при более высоком напряжении на электроде.

В первоначальном исследовании [29] при использовании пары материалов $I T O-\mathrm{NbO}_{x}$ наночастицы ITO недостаточно ослабляют БИК излучение вследствие того, что максимум их полосы поглощения расположен за пределами основной части солнечного БИК излучения. Группа продолжила поиски наиболее эффективных материалов. Наночастицы из восстановленных оксидов вольфрама $\mathrm{WO}_{3-x}$ или из цезиевой бронзы $\mathrm{Cs}_{0.33} \mathrm{WO}_{3}$ обладают высокой способностью подавления БИК излучения, потому что максимумы их полос поглощения находятся вблизи $1000 \mathrm{~nm}$ (рис. 8). Поэтому в следующей работе [30] была использована пара материалов $\mathrm{WO}_{3-x}-\mathrm{NbO}_{x}$. Нанокристаллы $\mathrm{WO}_{3-x}$ ослабляют БИК излучение, аморфный $\mathrm{NbO}_{x}$ ослабляет видимый свет.

Особое внимание уделено формированию структуры электрохромной пленки. Размер нанокристаллов $\mathrm{WO}_{3-x}$ равен $4.3 \mathrm{~nm}$. Сначала из этих частиц была сформирована регулярная пористая структура пористостью 71\% со средним радиусом пор $53 \mathrm{~nm}$. После этого пористая структура была заполнена аморфным $\mathrm{NbO}_{x}$. Полученная двухкомпонентная матрица имеет пористость 9\% при среднем радиусе пор $1.7 \mathrm{~nm}$ и радиусе капиллярных каналов $1.5 \mathrm{~nm}$. Непрерывная сеть связанных капилляр- 
Таблица 2. Изменение пропускания видимого света $\tau_{\mathrm{vis}}$, БИК излучения $\tau_{\mathrm{NIR}}$ и солнечной энергии $\tau_{\mathrm{sol}}$ в ходе электрохромного модулирования [30]

\begin{tabular}{c|l|c|c|c}
\hline \multicolumn{2}{c|}{ Состояние на рис. 15 } & $\tau_{\text {vis }}$ & $\tau_{\mathrm{NIR}}$ & $\tau_{\text {sol }}$ \\
\hline 1 & Светлое теплое & 0.93 & 0.91 & 0.92 \\
2 & Светлое холодное $(1 \mathrm{~min})$ & 0.73 & 0.36 & 0.54 \\
3 & Светлое холодное $(3 \mathrm{~min})$ & 0.54 & 0.16 & 0.35 \\
4 & Темное холодное & 0.22 & 0.07 & 0.14
\end{tabular}

ными каналами пор обеспечивает возможность перемещения ионов $\mathrm{Li}^{+}$по всей толщине электрохромной пленки. Толщина слоя $260 \mathrm{~nm}$.

Изготовленная таким способом двухкомпонентная электрохромная пленка проявляет независимое двухполосное модулирование солнечного излучения при изменении напряжения на ней. Спектры пропускания при различных напряжениях изображены на рис. 15 .

При подаче напряжения $4 \mathrm{~V}$ оба компонента $\left(\mathrm{WO}_{3-x}\right.$ и $\mathrm{NbO}_{x}$ ) полностью разряжены - часть свободных электронов из них удалена. Пленка пропускает видимый свет и БИК излучение и ее состояние светлое теплое. При понижении напряжения до $2.3 \mathrm{~V}$ постепенно возрастает концентрация свободных электронов в плазмонных нанокристаллах $\mathrm{WO}_{3-x}$. Это приводит к увеличению интенсивности плазмонного резонанса и постепенному ослаблению пропускаемого БИК излучения. Максимум полосы поглощения около $900 \mathrm{~nm}$. При этом ослабляется и часть видимого света, в основном в его правой „красной“ части спектра. В этом светлом холодном состоянии пленка блокирует значительную часть БИК излучения и пропускает видимый свет. При дальнейшем понижении напряжения от 2.3 до $1.5 \mathrm{~V}$ электроны и компенсирующие их ионы $\mathrm{Li}^{+}$внедряются внутрь $\mathrm{NbO}_{x}$. Это приводит к возникновению и постепенной интенсификации поляронного механизма ослабления видимого света. Пленка становится темной холодной. Она имеет серо-голубой цвет постепенно увеличивающей глубины.

Интегральные значения коэффициентов пропускания видимого света $\tau_{\text {vis }}$, БИК излучения $\tau_{\mathrm{NIR}}$ и их суммарной величины (солнечной энергии) $\tau_{\mathrm{s}}$ приведены в табл. 2. В темном холодном состоянии пленка практически полностью ослабляет БИК излучение.

Дальнейшие усилия коллектива были направлены на отработку технологии изготовления более дешевых и качественных мезопористых структур из наночастиц. Авторы получили наночастицы $\mathrm{WO}_{2.72}$ в виде стержней диаметром $\sim 5.3 \mathrm{~nm}$ и длиной $\sim 84 \mathrm{~nm}$ [31]. Использование таких наночастиц позволило изготовить однородную мезопористую структуру в виде пленки толщиной $300 \mathrm{~nm}$ на покрытой ITO пленке полиэтилентерефталата. Затем в эту пористую структуру методом химической конденсации был инфильтрован аморфный $\mathrm{NbO}_{x}$. В итоге изготовлена гибкая двухкомпонентная $\mathrm{WO}_{2.72}-\mathrm{NbO}_{x}$ электрохромная ячейка, позволяющая обеспечить динамическое двухполосное модулирование пропускаемого солнечного излучения. Спектры пропускания такой ячейки изображены на рис. 16. Они достаточно близки к аналогичным зависимостям на рис. 15. Отмечено, что композитная гибкая электрохромная ячейка обладает высокой циклической стабильностью - ее свойства не изменились после 2000 циклов.

Такие результаты позволяют сделать заключение, что в результате цикла исследований коллектив под руководством D.J. Milliron впервые реализовал устройство

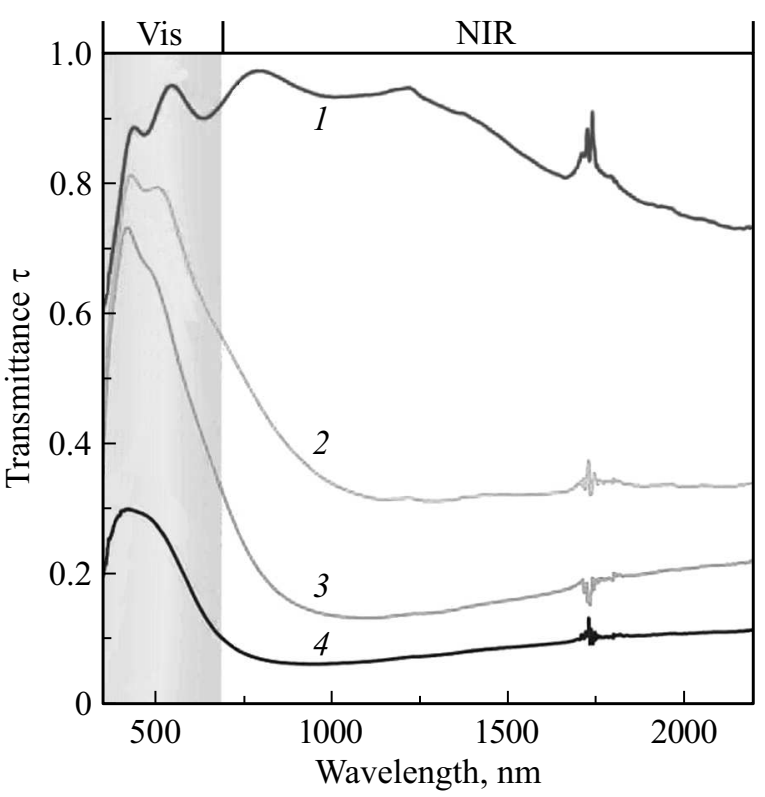

Рис. 15. Изменение спектра пропускания композитной двухкомпонентной $\mathrm{WO}_{3-x} \mathrm{NbOx}$ нанокристаллической пленки при изменении напряжения от 1.5 до $4 \mathrm{~V}$. Толщина пленки $260 \mathrm{~nm}$ [30]. Напряжение на пленке: 4 (1), 2.3 (2), 2.3 (3), $1.5 \mathrm{~V}$ (4). Состояние 2 зафиксировано через $1 \mathrm{~min}$ после переключения напряжения, состояние 3 - через $3 \mathrm{~min}$.

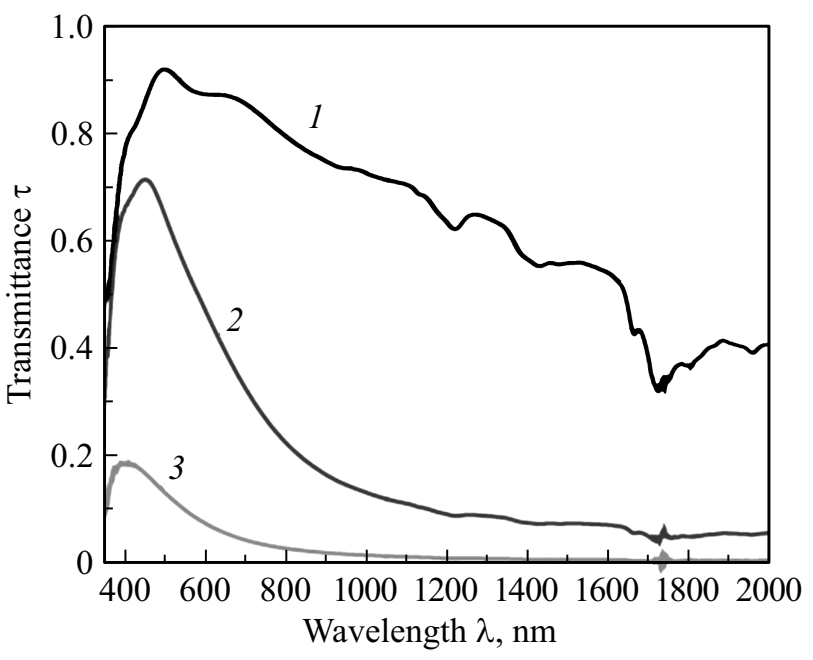

Рис. 16. Спектры пропускания гибкой композитной двухкомпонентной $\mathrm{WO}_{3-x} \mathrm{NbO}_{x}$ нанокристаллической пленки в трех характерных состояниях [31]. Напряжение на пленке: 4 (1), $2.4(2), 1.5 \mathrm{~V}(3)$. 
динамического независимого модулирования БИК излучения и видимого света, характеристики которого отвечают требованиям для реальных энергосберегающих умных окон.

Существенное достоинство использованной двухкомпонентной пористой электрохромной пленки состоит в том, что она может быть заполнена пластифицированным полимерным электролитом. Все это вместе взятое создает реальные предпосылки для коммерческой реализации таких устройств оконного размера.

Основной недостаток - значительная сложность изготовления двухкомпонентной электрохромной пленки. К этому времени уже было установлено, что в нанокристаллах вольфрамовых бронз $\mathrm{Cs}_{0.33} \mathrm{WO}_{3}$ одновременно могут сосуществовать два механизма поглощения солнечного излучения [15]. Основной механизм плазмонный резонанс с полосой поглощения с центром около $1550 \mathrm{~nm}$. Второй, вспомогательный - оптическое поглощение с полосой с центром около $880 \mathrm{~nm}$ при внедрении электронов и ионов $\mathrm{Li}^{+}$внутрь кристаллической решетки.

Разработки двухполосной электрохромной ячейки для динамического модулирования пропускаемого солнечного излучения были подхвачены и активно продолжены группой итальянских исследователей $[32,33]$.

В работе [32] двухполосная модуляция была реализована с более простой однокомпонентной электрохромной пленкой из триоксида вольфрама $\mathrm{WO}_{3}$. Пленка толщиной $1.2 \mu \mathrm{m}$ изготовлена из удлиненных нанокристаллов в виде стержней средним диаметром около $3 \mathrm{~nm}$ и длиной около $60 \mathrm{~nm}$. Пленка имеет однородную структуру типа войлок.

Результаты приведены на рис. 17, 18. На рис. 17 показано изменение спектра пропускания электрохромной ячейки при постепенном понижении напряжения на ней. На рис. 18 изображено соответствующее изменение значений интегральных коэффициентов пропускания видимого света $\tau_{\text {vis, }}$ БИК излучения $\tau_{\mathrm{NIR}}$ и их суммарной величины (солнечной энергии) $\tau_{\mathrm{s}}$.

В начальном состоянии (светлое теплое) ячейка пропускает БИК и видимое излучение. При понижении напряжения от 0 до $-0.4 \mathrm{~V}$ происходит плавное быстрое уменьшение пропускания БИК излучения, тогда как пропускание видимого света уменьшается очень незначительно. При напряжении $-0.4 \mathrm{~V}$ ячейка почти полностью ослабляет БИК излучение - состояние светлое холодное. При дальнейшем понижении напряжения происходит плавное снижение пропускания видимого света и достигается темное холодное состояние. В конечном темном холодном состоянии при напряжении $-1.8 \mathrm{~V}$ достигаются величины коэффициентов $\tau_{\mathrm{vis}}$ и $\tau_{\mathrm{NIR}}$, которые значительно меньше соответствующих данных в табл. 2.

Триоксид вольфрама $\mathrm{WO}_{3}$ является основным материалом для изготовления электрохромных стекол. В этих стеклах снижение пропускания видимого и БИК изучения всегда происходит одновременно (рис. 10) и объясняется поляронным механизмом ослабления излучения.

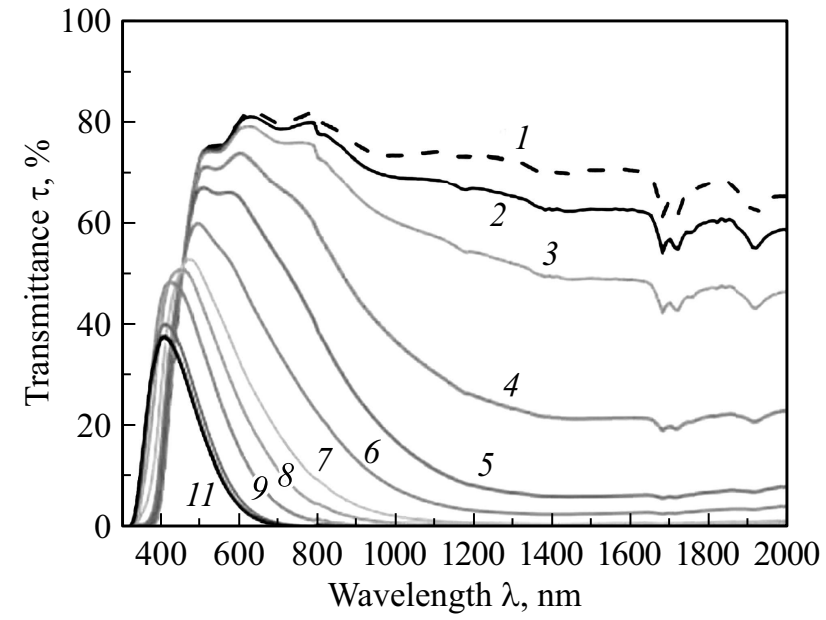

Рис. 17. Изменение спектра пропускания нанокристаллической пленки $\mathrm{WO}_{3}$ при увеличении отрицательного напряжения на ней от 0 до $-1.8 \mathrm{~V}$ [32]: $0(1),-0.1(2),-0.2(3),-0.3$ (4), $-0.4(5),-0.5(6),-0.6(7),-0.7(8),-1.0(9),-1.5(10)$, $-1.8 \mathrm{~V}(11)$.

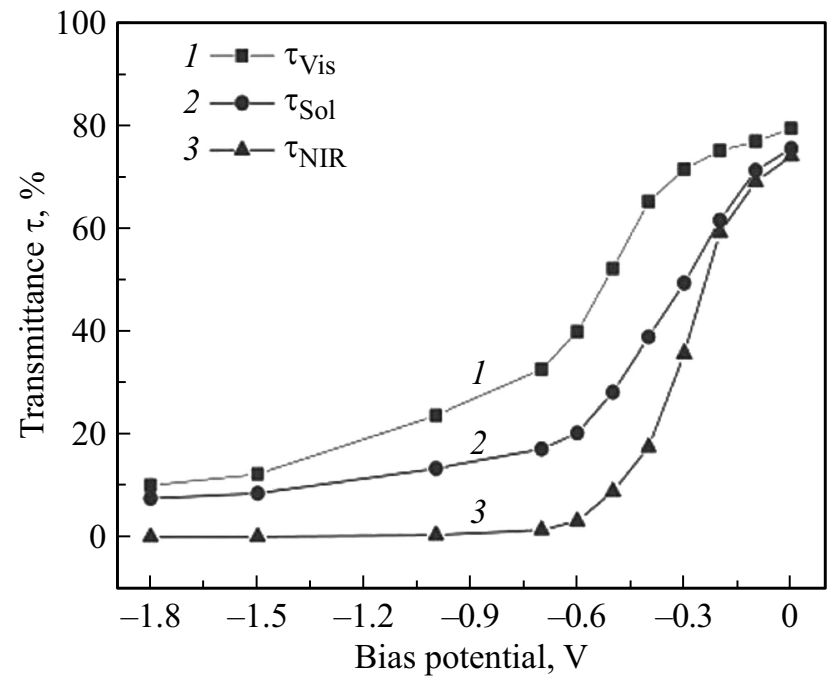

Рис. 18. Изменение интегральных коэффициентов пропускания видимого света $\tau_{\text {vis }}(1)$, солнечной энергии $\tau_{\text {sol }}(2)$ и БИК излучения $\tau_{\mathrm{NIR}}(3)$ нанокристаллической пленки $\mathrm{WO}_{3}$ в зависимости от напряжения на ней [32].

Чем вызвано и как объясняется раздельное ослабление БИК излучения и видимого света в данной работе? Авторы [32] объясняют такое явление чрезвычайно большим отношением поверхности к объему нанокристаллов удлиненной стержневой формы.

При понижении напряжения от 0 до $-0.4 \mathrm{~V}$ происходит емкостное накопление заряда наностержней электроны накапливаются в объеме, а ионы $\mathrm{Li}^{+}-$на их поверхности. Это приводит к постепенно возрастающему плазмонному ослаблению БИК излучения. При дальнейшем понижении напряжения от -0.4 до $-1.8 \mathrm{~V}$ ионы $\mathrm{Li}^{+}$внедряются внутрь кристаллической решетки 
$\mathrm{WO}_{3}$ и вступает в действие поляронный механизм ослабления видимого света.

Значительное влияние на характер процесса оказывает состав электролита. Полностью эффект раздельного модулирования БИК излучения и видимого света наблюдается при добавлении в электролит $\mathrm{LiClO}_{4}$ значительной доли иодистого лития LiI. В данном случае использована в качестве электролита смесь $0.7 \mathrm{M} \mathrm{LiClO}_{4}+0.3 \mathrm{M} \mathrm{LiI,}$ растворенная в смеси пропиленкарбоната и ацетонитрила $(70: 30)$. При отсутствии в смеси соли LiI или низком ее содержании (например, 0.005 M LiI) ослабление видимого света не происходит.

Затем авторы изготовили электрохромную ячейку из легированного ниобием $\mathrm{Nb}$ диоксида титана $\mathrm{TiO}_{2}$ [33]. Были получены четыре партии легированных $\mathrm{Nb}$ нанокристаллов $\mathrm{TiO}_{2}$ со средним размером около $10 \mathrm{~nm}$ и различным содержанием ниобия, а именно 0,5 , 10 и 15\%. Из четырех партий дисперсия в толуоле нанокристаллов с 10\%-ным содержанием $\mathrm{Nb}$ проявила самую высокую, характерную для плазмонного резонанса, поглощательную способность в диапазоне ИК излучения с максимумом около $2500 \mathrm{~nm}$. После спекания порошка нанокристаллов при температуре $430^{\circ} \mathrm{C}$ свойство локализованного плазмонного резонанса полностью пропадает.

Из нанокристаллов $\mathrm{TiO}_{2}$ с 10\%-ным содержанием $\mathrm{Nb}$ был изготовлен прозрачный мезопористый электрод толщиной $2.1 \mu \mathrm{m}$. В качестве электролита в электрохромной ячейке применили раствор $1 \mathrm{M} \mathrm{LiCl}+0.1 \mathrm{M} \mathrm{LiI}$ в диметилсульфоксиде. Оптические характеристики такой электрохромной ячейки при изменении катодного потенциала от 0 до $-4 \mathrm{~V}$ изображены на рис. 19.

На этом же рис. 19 в правой его части схематично изображены три характерных состояния электрохромной ячейки при катодных потенциалах соответственно $0,-3$ и $-4 \mathrm{~V}$. В отключенном состоянии при $0 \mathrm{~V}$ нанокристаллы не имеют электрического заряда и ионы $\mathrm{Li}^{+}$равномерно распределены по объему электролита.

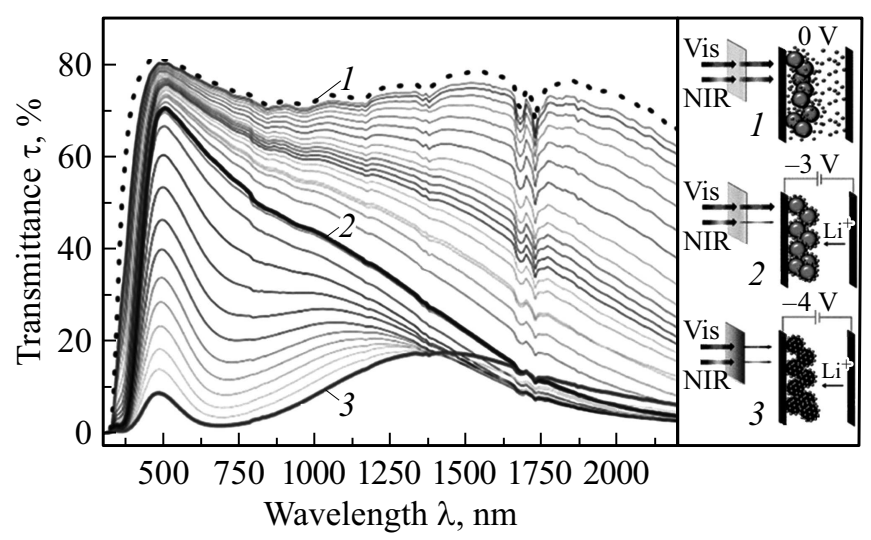

Рис. 19. Постепенное изменение спектральных характеристик однокомпонентной электрохромной пленки толщиной $2.1 \mu \mathrm{m}$ из легированных ниобием нанокристаллов $\mathrm{TiO}_{2}$ с $10 \%$-ным содержанием $\mathrm{Nb}$ при изменении катодного потенциала от 0 до $-4 \mathrm{~V}$ [33]: -0 (1), $-3(2),-4 \mathrm{~V}(3)$.

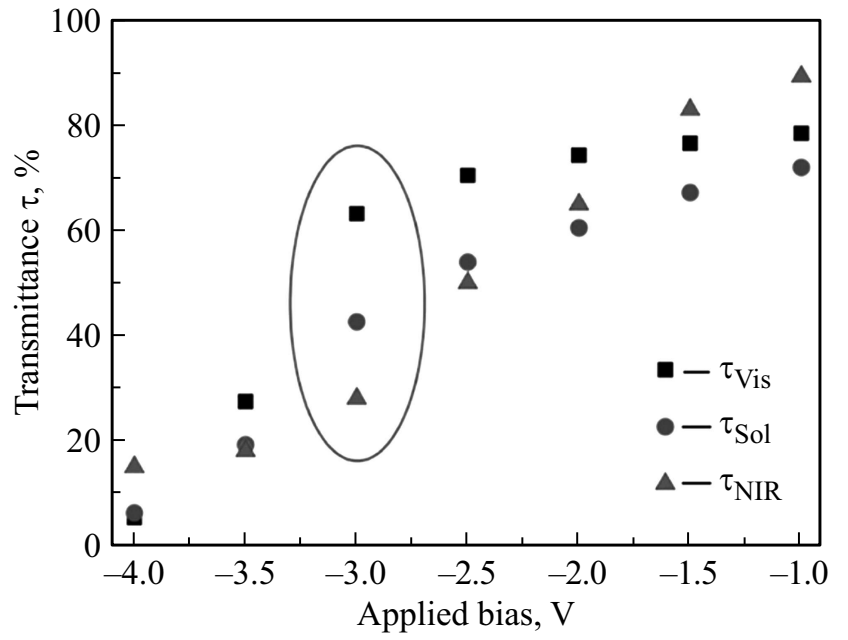

Рис. 20. Изменение интегральных коэффициентов пропускания видимого света $\tau_{\text {vis }}$, солнечной энергии $\tau_{\mathrm{s}}$ и БИК излучения $\tau_{\mathrm{NIR}}$ пленки из легированных ниобием нанокристаллов $\mathrm{TiO}_{2} \mathrm{c}$ $10 \%$-ным содержанием $\mathrm{Nb}$ при изменении катодного потенциала от -1 до $-4 \mathrm{~V}[33]$.

При увеличении катодного потенциала от 0 до $-3 \mathrm{~V}$ постепенно возрастает концентрация инжектированных электронов в нанокристаллах. Ионы $\mathrm{Li}^{+}$собираются около поверхности нанокристаллов для компенсации их отрицательного заряда, образуя двойной электрический слой. Максимум полосы поглощения вследствие увеличения частоты локализованного плазмонного резонанса сдвигается влево (голубой сдвиг) и происходит постепенное ослабление проходящего БИК излучения. Ослабление видимого света при этом умеренное.

При увеличении катодного потенциала выше $-3 \mathrm{~V}$ ионы $\mathrm{Li}^{+}$постепенно внедряются внутрь нанокристаллов. Это приводит к формированию и постепенному повышению интенсивности поляронного механизма поглощения излучения в диапазоне видимого света. При катодном потенциале $-4 \mathrm{~V}$ падающее солнечное излучение почти полностью поглощается во всем диапазоне длин волн. Электрохромная ячейка постепенно переходит из светлого теплого состояния (при $0 \mathrm{~V}$ ) к светлому холодному $(-3 \mathrm{~V})$ и далее к темному холодному $(-4 \mathrm{~V})$.

Соответствующее изменение интегрального пропускания электрохромной ячейки изображено на рис. 20. Здесь нужно отметить резкое изменение (излом) наклона зависимости коэффициента пропускания видимого света $\tau_{\text {vis }}$ при $-3 \mathrm{~V}$ и очень низкое его значение $(\sim 7 \%)$ при катодном потенциале $-4 \mathrm{~V}$.

Следует также отметить электрохромную двухкомпонентную гибридную систему в виде диспергированных в полимерной матрице из политиофена нанокристаллов ITO [34]. Размер нанокристаллов $\sim 5 \mathrm{~nm}$, содержание олова в них $13 \%$. Толщина пленки $\sim 900 \mathrm{~nm}$. Нанокристаллы ITO ослабляют БИК излучение с длиной волны более $1200 \mathrm{~nm}$ в результате плазмонного резонанса. При электрохимическом окислении под действием положительного напряжения пленка политиофена равномерно 
ослабляет видимый свет в результате поляронного эффекта.

Гибридная система при изменении напряжения имеет три характерных состояния: светлое холодное, светлое теплое и темное холодное. Но эти состояния при изменении напряжения располагаются в последовательности, отличной от аналогичных последовательностей в рассмотренных ранее электрохромных устройствах.

Существенным недостатком такой гибридной системы является быстрая деградация ее свойств в электрохимической ячейке, а также быстрое разрушение полимерной матрицы под действием солнечного УФ излучения [34]. Это исключает возможность ее использования в окнах до тех пор, пока эти недостатки не будут устранены.

\section{Список литературы}

[1] Майоров В.А. // Светопрозрачные конструкции. 2016. № 1. C. 21.

[2] Майоров В.А. // Светопрозрачные конструкции. 2016. № 2. C. 8.

[3] Bräuer G. // Surf. Coat. Techn. 1999. V. 112. № 1-3. P. 358. doi 10.1016/S0257-8972(98)00737-3

[4] Gläser H.J. // Appl. Optics. 2008. V. 47. № 13. P. C193. doi 10.1364/AO.47.00C193.

[5] Kleideiter G. // Function and Production of Coating on Architectural Glass. Basics and overview. Leybold optics. 2010. [Электронный ресурс] Режим доступа: http://www.leyboldoptics.com

[6] Mohelnikova J. // Nanocoatings and ultra-thin films. Technologies and applications / Ed. by Makhlouf A.S.H., Tiginyanu I. Woodhead Publishing Ltd., 2011. P. 182.

[7] SunGuard Advanced Architectural Glass. Technical Information. What you need to know to build with light. 2015 Guardian Industries Corp. 34 p. [Электронный ресурс] Режим доступа: http://www.sunGuardGlass.com

[8] Климов В.В. Наноплазмоника. М.: Физматлит, 2009. 480 с.

[9] Kriegel I., Scotognella F., Manna L. // Physics Reports. 2017. V. 674. № 1. P. 1. doi 10.1016/j.physrep.2017.01.003

[10] Agrawal A., Johns $R$ W., Milliron D.J. // Ann. Rev. Mat. Research. 2017. V. 47. N 1. P. 1. doi 10.1146/annurev-matsci070616-124259

[11] Govorov A.O., Richardson H.H. // Nano Today. 2007. V. 2. N 1. P. 30. doi 10.1016/S1748-0132(07)70017-8

[12] Adachi K., Miratsu M., Asahi T. // J. Mater. Research. 2010. V. 25. N 3. P. 510. doi 10.1557/JMR.2010.0075

[13] Machida K., Tofuku A., Adachi K. // Handbook of Functional Nanomaterials. V. 1: Synthesis and Modifications. Nova Science Publishers, Inc. / Ed. by Aliofkhazraei M. 2014. P. 199.

[14] Lounis S.D., Runnerstrom E.L., Llordés A., Milliron D.J. // J. Phys. Chem. Lett. 2014. V. 5. N 9. P. 1564. doi 10.1021/jz500440e

[15] Adachi K., Asahi T. // J. Mater. Research. 2012. V. 27. N 6. P. 965 . doi 10.1557/jmr.2012.25

[16] Berggren L., Azens A., Niklasson G.A. //. J. Appl. Phys. 2001. V. 90 . N 4. P. 1860 . doi 10.1063/1.1384853

[17] Niklasson G.A., Granqvist C.G. // J. Mater. Chem. 2007. V. 17. N 2. P. 127. doi 10.1039/B612174H
[18] Sumitomo Metal Mining Co., Ltd. Functional Inks : Nearinfrared Shielding Materials. [Электронный pecypc] Режим доступа: http://www.smm.co.jp/E/products/material/ink/

[19] Fuji Technical Information. Near Infrared Red Light, IR Shield, Absorb Materials (Heat Shielding, Absorbing Materials) Tungsten based Complex Oxide (Fuji EL MWO3 Series). [Электронный ресурс] Режим доступа: http://www.fuji-pigment.co.jp/en/IR_Shield_en.pdf

[20] Tani T., Hakuta S., Kiyoto N., Naya M. // Optics Express. 2014. V. 22. N 8. P. 9262. doi10.1364/OE.22.009262

[21] Naya M. // Nano Silver Pavement - Metamaterial film for heat-cut from sun light. [Электронный ресурс] Режим доступа: http://www.df.unipi.it/ fuso/italyjapan/abs/Naya.pdf

[22] Майоров B.A. // Светопрозрачные конструкции. 2017. № 6. C. 15.

[23] Granqvist C.G. // Thin Solid Films. 2014. V. 564. N 1. P. 1. doi 10.1016/j.tsf.2014.02.002

[24] Runnerstrom E.L., Llorders A., Lounisac S.D., Milliron D.J. // Chem. Commun. 2014. V. 50. № 73. P. 10555. doi 10.1039/C4CC03109A

[25] Garcia G., Buonsanti R., Runnerstrom E.L., Mendelsberg R.J., Llordes A., Anders A., Richardson T.J., Milliron D.J. // Nano Lett. 2011. V. 11. N 10. P. 4415. doi $10.1021 / \mathrm{n} 1202597 \mathrm{n}$.

[26] Garcia G., Buonsanti R., Lordes A., Runnerstrom E.L., Bergerud A., Milliron D.J. // Adv. Opt. Materials. 2013. V. 1. N 3. P. 215. doi 10.1002/adom.201200051

[27] Williams T.E., Chang C.M., Rosen E.L., Garcia G., Runnerstrom E.L., Williams B.L., Koo B., Buonsanti R., Milliron D.J, Helms B.A. // J. Mater. Chem. C. 2014. V. 2. N 17. P. 3328. doi 10.1039/C3TC32247E

[28] Pattathil P., Giannuzzi R., Manca M. // Nano Energy. 2016. V. 30. P. 242. doi 10.1016/j.nanoen.2016.10.013

[29] Llordés A., Garcia G., Gazquez J., Milliron D.J. // Nature. 2013. V. 500. N 7462. P. 323. doi 10.1038/nature 12398

[30] Kim J., Ong G.K., Wang Y., LeBlanc G., Williams T.E., Mattox T.M., Helms B.A., Milliron D.J. // Nano Letters. 2015. V. 15. N 8. P. 5574. doi 10.1021/acs.nanolett.5b02197

[31] Heo S., Kim J., Ong G.K., Milliron D.J. // Nano Letters. 2017. V. 17. N 9. P. 5756. doi 10.1021/acs.nanolett.7b02730

[32] Pattathil P., Scarfiello R., Giannuzzi R., Veramonti G., Sibillano T., Qualtieri A., Giannini C., Cozzoli P.D., Manca M. // Nanoscale. 2016. V. 8. N 48. P. 20056. doi $10.1039 / \mathrm{C} 6 \mathrm{NR} 07221 \mathrm{~F}$

[33] Barawi M., De Trizio L., Giannuzzi R., Veramonti G., Manna L., Manca M. // ACS Nano. 2017. V. 11. N 4. P. 3576. doi 10.1021/acsnano.6b06664

[34] Barile C.J., Slotcavage D.J., McGehee M.D. // Chem. Mater. 2016. V. 28. N 5. P. 1439. doi 10.1021/acs.chemmater.5b04811 